\title{
Hericium erinaceus - A Rich Source of Diverse Bioactive Metabolites
}

\author{
Deshmukh SK ${ }^{*}$, Sridhar $\mathrm{KR}^{2,3}$, and Gupta $\mathrm{MK}^{4}$ \\ ${ }^{1}$ TERI-Deakin Nano Biotechnology Centre, The Energy and Resources Institute, Darbari Seth Block, IHC \\ Complex, Lodhi Road, New Delhi, India \\ ${ }^{2}$ Department of Biosciences, Mangalore University, Mangalagangotri, Mangalore, Karnataka, India \\ ${ }^{3}$ Centre for Environmental Studies, Yenepoya (Deemed to be University), Mangalore, Karnataka, India \\ ${ }^{4}$ SGT College of Pharmacy, SGT University, Gurugram, Haryana, India
}

Deshmukh SK, Sridhar KR, and Gupta MK 2021 - Hericium erinaceus - A Rich Source of Diverse Bioactive Metabolites. Fungal Biotec 1(2), 10-38, Doi 10.5943/FunBiotec/1/2/2

\begin{abstract}
Hericium erinaceus (commonly known as lion's mane mushroom) is an edible mushroom used in traditional Chinese medicine. It is a prolific producer of diverse bioactive metabolites with neuroprotective and neuroregenerative properties (e.g. $\beta$-glucan polysaccharides, hericenones, erinacine terpenoids, isoindolinones, sterols, and myconutrients). Because of its anti-inflammatory properties and promotion of nerve growth factor (NGF) gene expression and neurite (axon or dendrite) outgrowth, $H$. erinaceus is used for the treatment of Alzheimer's as well as Parkinson's diseases. This review provides a comprehensive account of the bioactive compounds from $H$. erinaceus (both from the fruit bodies and mycelia) and their biological activities such as neuroprotective functions, cytotoxicity, anticarcinogenic, antidiabetic, antimicrobial, and herbicidal activities.
\end{abstract}

Keywords - Alzheimer's disease - anticancer agents - antidiabetic - anti-inflammatory antimicrobial - erinacine terpenoids - herbicidal - hericenone - neurite outgrowth neuroprotection - Parkinson's disease

\section{Introduction}

In recent years, research on $H$. erinaceus has been focused on its antidepressant-like effects to treat depressive disorders (Yao et al. 2015, Chiu et al. 2018, Ryu et al. 2018). This review focuses on bioactive compounds of different strains of $H$. erinaceus. Primary emphasis is laid on the pharmacological activities of various metabolites of $H$. erinaceus along with bioactive compounds and their biological properties.

Hericium erinaceus (Bull.) Pers., is a macro fungus belonging to the family Hericiaceae (Russulales, Agaricomycetes, Basidiomycota). Hericium erinaceus is an edible mushroom possesses several medicinal properties. It has many common names: bear's head mushroom, bearded hedgehog mushroom, bearded tooth fungus/mushroom, hog head fungus, Hou Tou Gu (Chinese), lion's mane mushroom, monkey head mushroom, old man's beard mushroom, Pom Pom Mushroom, Satyr's beard fungus, white beard mushroom and Yamabushitake (Japanese). It is reported from China, Japan, Europe, and North America; found on dead oak, walnut, beech, maple, sycamore, and other broadleaf trees. It is most frequently found on logs or stumps and has a long 
history of usage in traditional Chinese medicine (Venturella et al. 2021). Bioactive constituents of $H$. erinaceus include alkaloids, fatty acids, terpenoids, phenolics, steroids, pyranones, and about 80 small compounds are isolated from $H$. erinaceus (Zhang 2016). Purified bioactive metabolites of the fruit body or mycelia of $H$. erinaceus possess a wide range of biological activities viz. anticancer (Wang et al. 2001, Zhang et al. 2020), antidiabetic (Yi et al. 2015), antihyperglycemic (Liang et al. 2013), anti-inflammatory (Mori et al. 2015), antimicrobial (Zhang et al. 2015a), antioxidant (Rahman et al. 2014), and hypolipidemic properties (Yang et al. 2003). In addition, $H$. erinaceus has been investigated as a potential treatment option in cognitive impairments (Mori et al. 2009), Alzheimer's disease (Tsai-Teng et al. 2016), Parkinson's disease (Kuo et al. 2016), ischemic stroke (Lee et al. 2014), and presbycusis (Chan et al. 2019). In recent years, research has been focused on its antidepressant-like effects for treating depressive disorders (Yao et al. 2015, Chiu et al. 2018, Ryu et al. 2018). This review focuses on bioactive compounds of different strains of $H$. erinaceus. This review highlights the pharmacological activities of metabolites derived from H. erinaceus and their biological properties.

\begin{tabular}{|ll|}
\hline Box 1 Impact of Hericium erinaceus in human health and wellbeing \\
- & Improves brain health \\
- & Fight anxiety and depression \\
- & Anti-inflammatory \\
- & Supports the health and good circulation \\
- & Supports fat burning and healthy metabolism \\
- & Improves digestive health \\
- & Anticancer properties \\
& Improves energy levels \\
\hline
\end{tabular}

\section{Stimulation of nerve growth factor}

The nerve growth factor (NGF), a polypeptide, is a member of the neurotrophin family. NGF is involved in the progress as well as maintenance of neurons in the peripheral nervous system and is essential for the functions of cholinergic neurons in the central nervous system (CNS). An optimum supply of NGF from the cortex and the hippocampus is required for proper function and morphology of basal forebrain cholinergic neurons (BFCNs). Age-dependent degeneration BFCNs contributes significantly to cognitive decline in AD. The agents that increase the level of NGF showed improvement in cognitive functions and AD (Salehi et al. 2004, Aloe et al. 2012). Several metabolites from $H$. erinaceus have shown significant CNS activity, such as improvement in cognitive function and increase in NGF activity, thus investigated for the treatment of dementia and Alzheimer's disease (AD).

\section{Hericenones}

Hericenones (benzyl alcohol derivatives) are aromatic compounds obtained from the fruit bodies of $H$. erinaceus. The fresh fruit bodies of the mushroom were extracted with acetone followed by recurrent chromatography of chloroform-soluble fractions (chloroform, then ethyl acetate) crude extract subject to HPLC (High-performance liquid chromatography) filled with ODS column to yield hericenones. Hericenones A (1) and B (2) were isolated during 1990 without their neurite outgrowth activity (Kawagishi et al. 1990). Novel compounds, hericenones C (3), D (4) and E (5) were purified from $H$. erinaceus (Kawagishi et al. 1991). Compounds (3-5) displayed stimulating activity towards the synthesis of NGF in vitro. In their presence $(3-5)(33 \mu \mathrm{g} / \mathrm{mL})$, astroglial cells of mouse secreted 10.8, 23.5, and $13.9 \mathrm{pg} / \mathrm{mL}$ of NGF into the medium, respectively. The extent of activity for (4) was comparable to the epinephrine, a potent stimulator. 
However, the activity of (3) and (5) are lower than (4). Interestingly, the variation in the activity of these compounds is rely on the length of chain and the double bond of the fatty acid (Kawagishi et al. 1991).

Hericenone E (5) (Fig. 1) was isolated from the fruit bodies of $H$. erinaceus. It has the capability to stimulate in vitro secretion of NGF in rat pheochromocytoma cells with two-fold higher than the positive control. Neuritogenesis was partially blocked by the receptor of tyrosine kinase (Trk) inhibitor (K252a) indicating the neuritogenic activity was not exclusively by the NGF. Hericenone $\mathrm{E}$ is known to increase the phosphorylation of extracellular-signal-regulated kinases (ERKs) as well as protein kinase B (Akt). Hericenone E (5) potentiated the NGF-induced neuritogenesis in PC12 cells via the MEK/ERK and PI3K/Akt pathways (Phan et al. 2014). Novel chroman, hericenone $\mathrm{F}(\mathbf{6}), \mathrm{G}(7)$, and $\mathrm{H}(8)$ were also purified from $H$. erinuceum. In the presence of hericenones $\mathrm{H}(\mathbf{8})$ at $33 \mu \mathrm{g} / \mathrm{mL}$, mouse astroglial cells secreted $45.1 \mathrm{pg} / \mathrm{mL}$ NGF into the culture medium (Kawagishi et al. 1993, Ma et al. 2010).

Three new compounds, hericenone I (9) and hericenone J (10) 3-hydroxyhericenone F (11), (Fig. 1) were purified from the mushroom $H$. erinaceus. Compounds (11) displayed significant dose-dependent protective action against tunicamycin- and thapsigargin-toxicity at concentrations up to $10 \mu \mathrm{g} / \mathrm{mL}$ in the assay against endoplasmic reticulum (ER) stress-dependent apoptosis. The ER stress was elicited by incorporation of thapsigargin or tunicamycin into the culture medium of Neuro-2a cells. Thapsigargin is an inhibitor of ER $\mathrm{Ca}^{2}+$-ATPase that causes depletion of $\mathrm{Ca} 2+$ in the ER, while tunicamycin is one of the inhibitors of N-glycosylation to glycoproteins and it is responsible for protein-misfolding in the ER. The results indicate that (11) could protect the neuronal cells by attenuating the ER stress by inducing apoptotic pathways on neural cells (Ueda et al. 2008) and may be helpful in the management of Alzheimer's disease.

Diling et al. (2017) purified 3-hydroxyhericenone F (11) (Fig. 1), which downregulates the $\beta$ site of $\beta$-amyloid precursor protein (APP) cleaving enzyme 1 (BACE1) and decreases the serum cytokines (IFN- $\gamma$, IL-1 $\beta$, IL-17 $\alpha$ ) level, tumor necrosis factor (TNF- $\alpha$ ) and production of reactive oxygen species (ROS). Hence, it confirms that the mushrooms enriched either hericenones ameliorate amyloid beta $(\mathrm{A} \beta)$ pathology as well as oxidative stress in Alzheimer's disease. Dilinoleoyl-phosphatidylethanolamine (DLPE) (12) is a phosphatidylethanolamine bearing two linoleic acids, and was purified from $H$. erinuceum. The DLPE can protect neuronal cells from ER stress-induced cell death, and the PKC pathway is involved in the protective mechanism (Nagai et al. 2006).

Another new compound isohericerinol A (13) (Fig. 1) along with previously reported compounds such as hericerin (14), N-de-phenylethyl isohericerin (15) and corallocin A (16) were extracted from the fruit bodies of $H$. erinaceus. The compound isohericerinol A (13) increased the production of nerve growth factor (NGF) strongly in C6 glioma cells compared to isohericerinol A (13) and corallocin A (16). Increase in NGF production by these compounds promote the neurite outgrowth in N2a neuronal cells. According to Ryu et al. (2021), the Western blot analysis confirmed increased expression of protein by NGF, synaptophysin (SYP) and brain-derived neurotrophic factor (BDNF) in C6-N2a cells.

\section{Erinacines}

Novel diterpenoids, erinacines A (17), B (18), and C (19) (Fig. 2) were isolated from the cultured mycelia of $H$. erinaceus. In the bioassay of mouse astroglia cells with erinacines A-C (1719) $(1.0 \mathrm{mM})$, the quantity of NGF secretion into the medium was $250.1,129.7$, and $299.1 \mathrm{pg} / \mathrm{mL}$, respectively. These activities were much more potent $(69.2 \mathrm{pg} / \mathrm{mL}$ at $1.0 \mathrm{mM})$ than known potent stimulator epinephrine (positive control) (Kawagishi et al. 1994). The biologically active compound erinacine A (17) has the capacity to decrease the ischemic injury in brain. Studied carried out in vitro showed that erinacine A can decelerate the cerebral ischemic brain injuries via inactivation of pathways: iNOS/RNS and p38 MAPK/CHOP. Erinacine A is also mediating the antioxidative and anti-inflammatory functions during an intermittent ischemic brain injury. Thus, compounds derived from Hericium (e.g. erinacine A) are capable to enhance the synthesis of NGF 
as well as induce neuroprotection, whereas its polysaccharides are capable to scavenge the ROS (Lee et al. 2014).<smiles>COc1cc2c(c(O)c1C/C=C(\C)CC(=O)C=C(C)C#N)COC2=O</smiles><smiles>COc1cc2c(c(O)c1C/C=C(\C)CC(=O)C=C(C)C)CN(Cc1ccccc1)C2=O</smiles><smiles>COc1cc(CO)c(C=O)c(O)c1C/C=C(\C)CC(=O)C=C(C)C</smiles>

R= palmytoyl , Hericenone C (3) $\mathbf{R}=$ stearoyl, Hericenone D (4) $\mathbf{R}=$ linoleoyl, Hericenone E (5)<smiles>COc1cc(CO)c(C=O)c2c1CCC(C)(CC(=O)C=C(C)C)O2</smiles>

$\mathbf{R}=$ palmytoyl , Hericenones $\mathbf{F}(6)$

$\mathbf{R}=$ stearoyl, Hericenones $\mathbf{G}$ (7) $\mathbf{R}=$ linoleoyl, Hericenones H (8)<smiles>[R][R]([H])c1cc(OC)c2c(c1)OC(C)(CC(=O)C=C(C)C)CC2</smiles>

Hericenone I (9)<smiles>COc1cc2c(c(O)c1C/C=C(\C)C[C@H](O)C=C(C)C)C(=O)OC2</smiles><smiles>CCCCCCCCCCCCCCCC(=O)OCc1cc(OC)c(O)c2c1OC1(C)CC(C=C(C)C)C(O)C21O</smiles>

Hericenone J (10)

3-Hydroxyhericenone F (11)

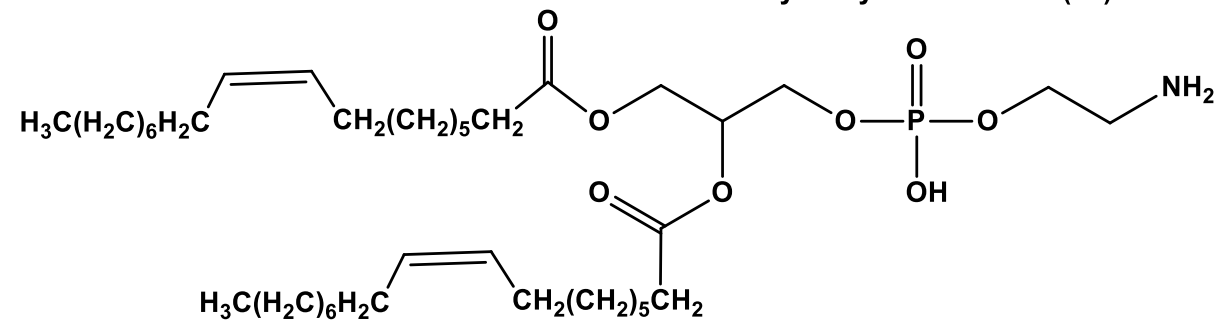

Dilinoleoyl-phosphatidylethanolamine (12)<smiles>COc1cc2c(c(O)c1CCO)CN(CCc1ccccc1)C2=O</smiles><smiles>COc1cc2c(c(O)c1C/C=C(\C)CCC=C(C)C)C(=O)N(CCc1ccccc1)C2</smiles>

Isohericerinol A (13)<smiles>COc1cc2c(c(O)c1C/C=C(\C)CCC=C(C)C)CNC2=O</smiles>

N-de-phenylethyl isohericerin (15)<smiles>COc1cc2c(c(O)c1C/C=C(\C)CC/C=C(\C)C(=O)O)COC2=O</smiles>

Corallocin A (16)

Fig. 1 - Hericenones isolated from Hericium erinaceus.

The effects of erinacine A-enriched $H$. erinaceus mycelia (HE-My) on the pathological changes in APPswe/PS1dE9 transgenic mouse model of Alzheimer's disease were studied. After 30 days of oral administration (300 $\mathrm{mg} / \mathrm{kg} /$ day) to 5 -months-old female transgenic mice (APPswe/PS1dE9), it was established that HE-My and its ethanol extracts (HE-Et) has the capacity to attenuate the burden of cerebral $A \beta$ plaque (Tsai-Teng et al. 2016). It is interesting to note that 
the portion of attenuated plaque is a non-compact structure. The HE-My as well as HE-Et have increased the level of insulin-degrading enzyme in the cerebral cortex, while in the cerebral cortex and hippocampus, the number of astrocytes and plaque-activated microglia decreased. Administration of HE-My and HE-Et promoted hippocampal neurogenesis and increased the ratio of NHF-NGF precursor (pro-NGF). According to Tsai-Teng et al. (2016), such administration in APPswe/PS1dE9 transgenic mice improved the activity of daily living skills.

A novel diterpenoid, erinacine D (20) (Fig. 2), along with the previously known compounds (erinacines $\mathrm{A}, \mathrm{B}$, and $\mathrm{C}$ ) were isolated from the mycelia of $\mathrm{H}$. erinaceus. The compound erinacine D (20) showed stimulating activity to NGF-synthesis by rat astroglial cells; the amount of NGF secreted into the culture medium in the presence of $4(1.67 \mathrm{mM})$ was $141.5 \mathrm{pg} / \mathrm{mL}$. This activity was stronger $(69.2 \mathrm{pg} / \mathrm{mL}$ at $1.0 \mathrm{mM})$ than a positive control epinephrine (Kawagishi et al. 1996a). Compounds erinacines E (21), F (22), and G (23) were purified from the mycelia of H. erinaceus. The compounds (21 and 22) showed powerful stimulating activity against the NGF synthesis by astroglial cells. In the bioassay using rat astroglial cells, the amounts of NGF secreted into the medium in the presence of $(\mathbf{2 1})$ and $(\mathbf{2 2})$ at $5.0 \mathrm{mM}$ were 105 and $175 \mathrm{pg} / \mathrm{mL}$, respectively. These activities were stronger $(70.2 \mathrm{pg} / \mathrm{mL}$ at $1.0 \mathrm{mM})$ than the known potent stimulator epinephrine used as a positive control (Kawagishi et al. 1996b).

Two erinacine derivatives $(\mathbf{2 4}, \mathbf{2 5})$ (Fig. 2) purified from the mycelia of $H$. erinaceus were reported to induce the biosynthesis of NGF, which is useful to treat dementia (Shimada et al. 1996). Similarly, the other two erinacine diterpenoids $(\mathbf{2 6}, \mathbf{2 7})$ from the mycelia of $H$. erinaceus were also reported to induce the production of NGF (Kawagishi et al. 1995). Bioactive cyatha-3, 12-diene (28) along with its isomer (29) was purified from the mycelia of $H$. erinaceus serves as an intermediate of cyathane diterpenoids (Kenmoku et al. 2001). Biotransformation capability of erinacine E (21) was evaluated using 81 microbes. Among the tested microbes, Caladariomyces fumago (ATCC 16373) was capable to transform erinacine E (21) into a new analog CP-412,065 (30) and the conversion rate was $29 \%$ (Saito et al. 1998).

Two new diterpenoids, erinacines H (31), and I (32) (Fig. 2), were purified from the mycelia of $H$. erinaceus. The compound erinacines $\mathrm{H}(\mathbf{3 1})$, showed stimulating activity to synthesize NGF using astroglial cells. The amounts of NGF $(31.5 \mathrm{pg} / \mathrm{mL})$ secreted into the medium in the presence of $33.3 \mu \mathrm{g} / \mathrm{mL}$ of $(\mathbf{3 1})$, was five times greater than those in the absence of the compound (Lee et al. 2000). According to Mori et al. (2008), the ethanol extract of $H$. erinaceus stimulated NGF mRNA as well as protein levels in human astrocytoma cells (1321-N1) and stimulated neurite outgrowth in pheochromocytoma cells (PC12) by promoting c-Jun N-terminal kinase activity. The aqueous extract of $H$. erinaceus contained neuroactive compounds, which induced NGF-synthesis and promoted neurite outgrowth in NG108-15 cells. The extract also enhanced the neurite outgrowth stimulation activity of NGF when applied in combination. The aqueous preparation of $H$. erinaceus showed neurotrophic but not neuroprotective activity (Lai et al. 2013).

A known compound 3,4-dihydro-5-methoxy-2-methyl-2-(4'-methyl-2'-oxo-3'-pentenyl)9(7H)-oxo-2H-furo[3,4-h]benzopyran (33) (Fig. 2), was extracted from the fruit bodies of $H$. erinaceus. This compound (33) displayed activity of high neurite outgrowth-promoting in NGFinduced cells (PC12) (Zhang et al. 2015b). Compounds such as 4-chloro-3,5-dimethoxybenzoic methyl ester (34) (Fig. 2), and erinacine A (17) were purified from the methhanolic extract of $H$. erinaceus mycelia. The compounds (17 and $\mathbf{3 4})$ efficient in protection of neuronally-differentiated pheochromocytoma cells (PC12) against deprival of NGF. The compound (17) capable to mimic the neuritogenic activity of NTs in the neurons of primary rat cortex. Similarly, the compounds (17 and 34) were also capable to potentiate the NGF-induced outgrowth of neurite devoid of the stimulation of NGF synthesis in PC12 cells. The cellular signaling pathways disclosed that NGFinduced neurite outgrowth is stimulated by compounds (17 and 34) fully by TrkA, while partially Erk1/2 (Zhang et al. 2017).

Previously unknown erinacine Z1 (35) (Fig. 3), along with known compounds erinacine A (17), erinacine B (18), erinacine C (19) were retrieved from the mycelium of $H$. erinaceus, while a known compound CJ14.258 (36) was retrieved from mycelium of Hericium flagellum (Rupcic et al. 
2018). None of the tested compounds showed intrinsic neurothrophic activity, stimulating neurite outgrowth directly from cultured PC12 cells; compounds (17-19, 35, 36) enhanced the neurotrophin production in astrocytic cells. Promoting the effect of cyathane diterpenoid derivatives on BDNF expression was also observed. Since erinacines can stimulate the transcription of both investigated neurothrophins, it suggests an upstream target, which is common to upstream events of NGF as well as BDNF induction (Rupcic et al. 2018).

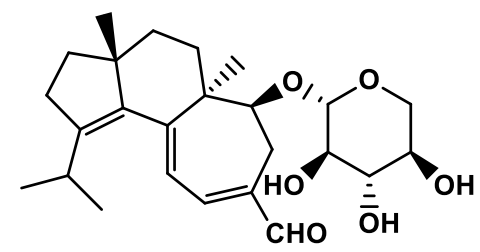

Erinacine A (17)

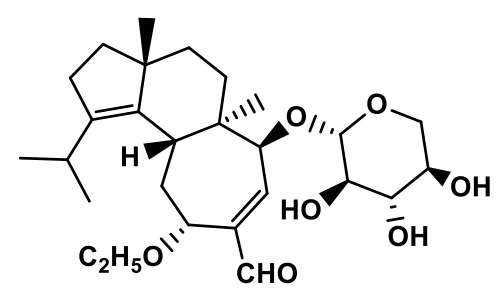

Erinacine D (20)
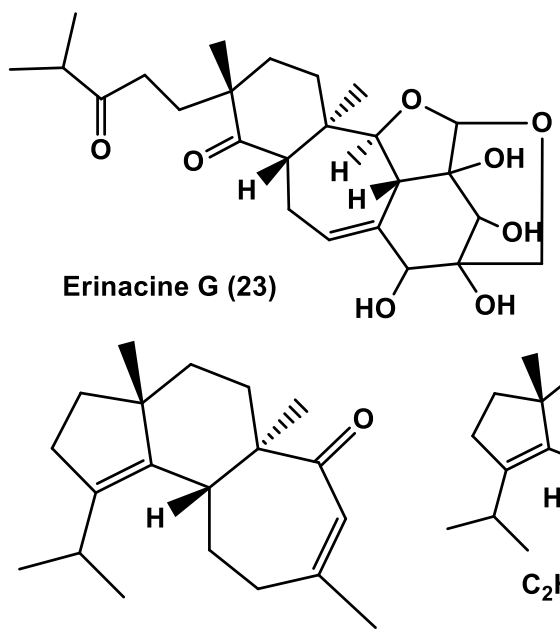

Erinacine diterpenoids (26)

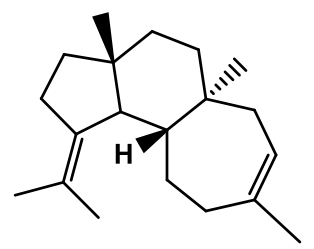

Cyatha-3, 12-diene's isomer (29)

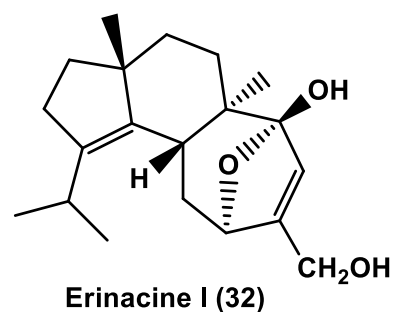

Erinacine I (32)

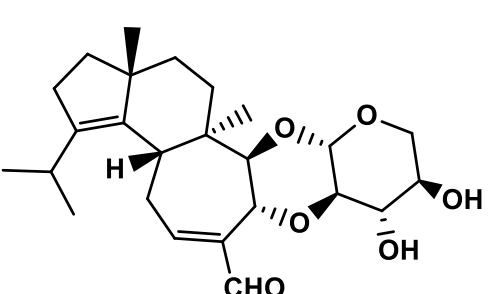

Erinacine B (18)

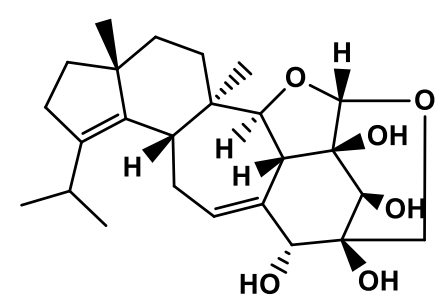

Erinacine E (21)

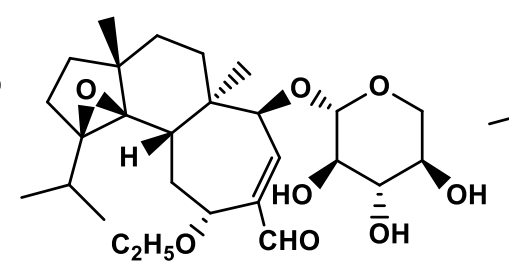

Erinacine derivative (24)

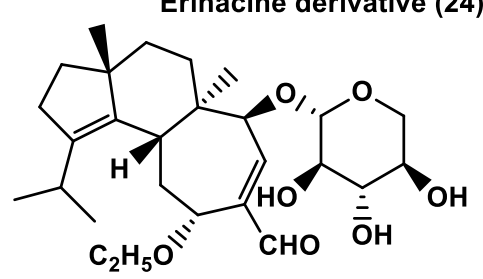

Erinacine diterpenoids (27)

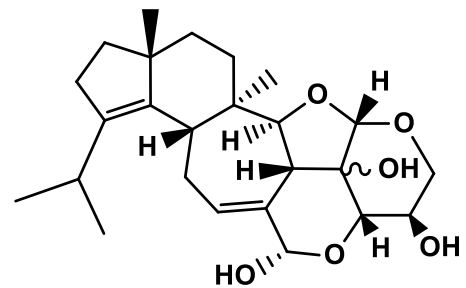

CP-412,065 (30)<smiles>COc1cc2c(c3c1CCC(C)(CC(=O)C=C(C)C)O3)C(=O)OC2</smiles>

3,4-Dihydro-5-methoxy-2-methyl-2 -(4'-methyl-2'-oxo-3'-pentenyl)-9(7H) -oxo-2H-furo[3,4-h]benzopyran (33)

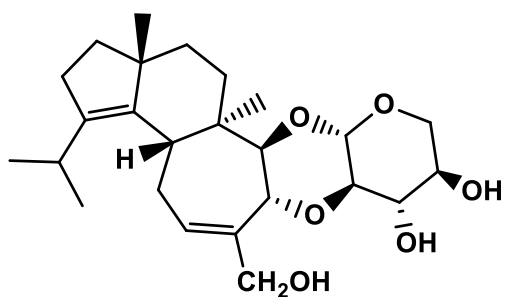

Erinacine C (19)
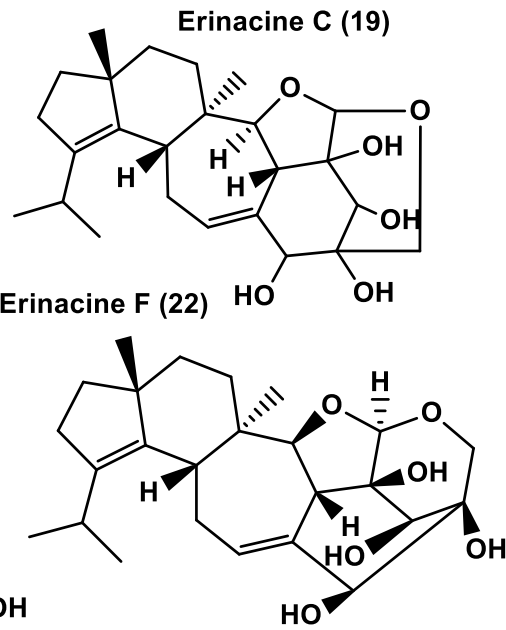

Erinacine derivative (25)

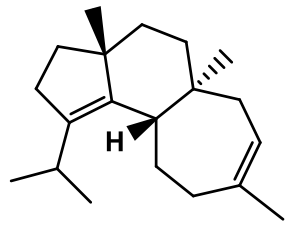

Cyatha-3, 12-diene (28)

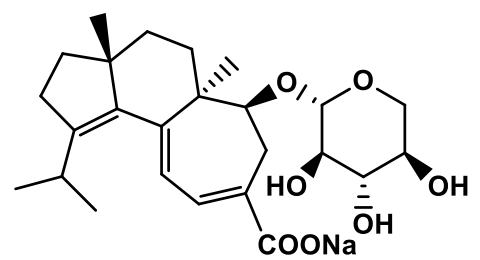

Erinacine H (31)<smiles>COC(=O)c1cc(OC)c(Cl)c(OC)c1</smiles>

4-Chloro-3,5-dimethoxybenzoic methyl ester (34)

Fig. 2 - Erinacines isolated from Hericium erinaceus. 
Three new cyathane diterpenes erinacines T-V (37-39) (Fig. 3), and two previously reported cyathane diterpenes erinacine $\mathrm{P}$ (40) were extracted from the liquid cultures of $\mathrm{H}$. erinaceus. The compounds (37-40) showed significant neurotrophic effects in the range of $2.5-10 \mu \mathrm{M}$ as compared with a control group. The percentage of neurite-bearing cells for cells treated with compounds (3740) at $10 \mu \mathrm{M}$ reached $43.7,76.31,65.3$, and $48.3 \%$, respectively. The NGF is used as a positive control with neurite-bearing cells of $40.3 \%$ at the concentration of $40 \mathrm{ng} / \mathrm{mL}$ (Zhang et al. 2018).

The peripheral nerve injury (PNI) is one of the significant health concerns. The NGF is known to play pivotal role in the growth, survival and maintenance of different neurons in the nervous system. The study of neuroprotective effects (NPE) of H. erinaceus and NGF against the mouse PNI model revealed that $H$. erinaceus shows a higher NPE than the NGF. The bioactive comounds of $H$. erinaceus avoid the death of neurons by regeneration of their axons leading to neuroprotection and neuro-regeneration help treating PNI. Further evaluation of bioactive compounds of $H$. erinaceus as a prospective source to cure PNI are necessary (Üstün \& Ayhan 2019). Trovato et al. (2016) showed evidence of the neuroprotective potential of $H$. erinaceus on oral administration to the rats. In the brain of those rats treated with fungus, induction of LXA4 was maximum in cortex and hippocampus, striatum and cerebellum.

A recent clinical trial has been performed to assess the capability of $H$. erinaceus various neurological disorder (e.g. anxiety, binge eating, depression and sleep disorders) (Vigna et al. 2019). A total of 77 subjects affected by obesity with one or more mood disorders was evaluated to receive three capsules of an $H$. erinaceus as dietary supplement daily up to two months with a lowcalorie diet regime. The administered fungal extract was with $80 \%$ mycelia and $20 \%$ fruit body. Prior to treatment, after the one and two months, the above-referred ailments were assessed (Symptom Checklist-90, Zung's Self-Rating Depression Scale, Zung's Self-Assessment Anxiety Scale, and Binge Eating Scale or BES). All the studies revealed significant improvements disorders (depression, anxiety, and sleep quality) in the H. erinaceus treated group. Further, concerning the serum balance in brain-derived neurotrophic factor (BDNF) and its precursor pro-BDNF, increased circulating pro-BDNF levels was evident. Still, clarifications are needed to understand whether these neurotrophins could be used as biomarkers in mood disorders (Vigna et al. 2019).

\section{Effects on dementia and Alzheimer's disease}

Dementia is a CNS disorder characterized by severely decline in mental ability which affect normal daily life of patients. Alzheimer's disease (AD) is the most common cause of dementia. AD is the fifth-leading cause of death among adults aged 65 years and older and is also a leading cause of disability and morbidity (Alzheimer's Association, 2019). Some of the bioactive isolated from Hericium were found active against Alzheimer's disease and are illustrated below.

A new sesterterpene, erinacine S (41) (Fig. 3), and, erinacine A (17) (Fig. 2), were purified from the ethanol extract obtained from the mycelia of $H$. erinaceus. A 30-day oral trial of erinacines $A(\mathbf{1 7})$ and $S(\mathbf{4 1})$ has attenuated the $A \beta$ plaque burden in the brains of 5-month-old female transgenic mice APP/PS1. In addition, erinacines A and S increased significantly the level of insulin-degrading enzymes in the cerebral cortex (Chen et al. 2016). Compounds (17 and 41 ) reduced the cortical and hippocampal amyloid plaque growth, promoted hippocampal neurogenesis putatively by inhibition of glial cells and increased insulin-degrading enzyme (IDE) expression in the APP/PS1 mice. However, only compound (17) was capable to decrease A $\beta$ production as well as the initiation of plaque formation. In addition, erinacine A recovers the behavioral deficits in the APP/PS1 mice. These suggest that the compound (17) may possesses therapeutic potential to treat Alzheimer's disease (Tzeng et al. 2018). Pharmacokinetics of compound (41), on oral dosing at $2.395 \mathrm{~g} / \mathrm{kg} \mathrm{BW}$ (H. erinaceus mycelial extract equivalent to $50 \mathrm{mg} / \mathrm{kg}$ body weight) of compound (41) in the male Sprague-Dawley rats was $15.13 \%$. The leading site of compound (41) absorption was stomach, while the primary route of elimination of the compound (41) is the fecal excretion. This was the first study to demonstrate that compound (41) could enter the blood-brain barrier of rats as well as support the development of $H$. erinaceus mycelia to treat the neurological disorders (Hu et al. 2019). 
A new cyathane-xyloside derivative named erinacine R (42) (Fig. 3), was isolated from the mycelia of $H$. erinaceus (Ma et al. 2008). Occurrence of extract of $H$. erinaceus in culture media supported the development of cerebellar neural cells (in vitro) by stimulating regulatory processes of myelinogenesis (Kolotushkina et al. 2003), which may be helpful in degenerative neuronal disorders such as Alzheimer's disease and peripheral nerve regeneration.

The $H$. erinaceus being a medicinal mushroom, which improves the recognition memory in mice. Using the HPLC-UV-ESI/MS analyses, the quantities of erinacine A (17) and hericenones C (3) and D (4) in the extracts of $H$. erinaceus were standardized to test against the animal model towards physiological aging. Oral administration up to two-months with $H$. erinaceus, the age decline of recognition memory reversed. The doublecortin (DCX) immunohistochemistry and proliferation of cell nuclear antigen (PCNA) in the hippocampus and cerebellum in experimental mice resulted in a positive effect of $H$. erinaceus of neurogenesis (Ratto et al. 2019).

Li et al. (2020) conducted a clinical trial to study the safety and efficacy of mycelia of the $H$. erinaceus enriched with $5 \mathrm{mg} / \mathrm{g}$ erinacine A++. The patients with mild Alzheimer's disease consumed three capsules daily (lyophilized mycelia of $350 \mathrm{mg} /$ capsule containing $5 \mathrm{mg} / \mathrm{g}$ erinacine A). This study involved a 3-weeks-no-drug screening period, followed by a 49-weeks double-blind treatment with two parallel groups where the patients were randomized either three mycelial capsules per day or identically appearing placebo capsules. The score showed intellectual health performance such as Cognitive Abilities Screening Instrument (CASI), Mini-Mental State Examination (MMSE), and Instrumental Activities of Daily Living (IADL) of the patients significantly increased by consumption of the capsules then the placebo group. This trial was performed based on various in vivo and in vitro studies that erinacine A (17) has positive impacts on the dementia ( $\mathrm{Li}$ et al. 2020).

The beneficial effects of $H$. erinaceus have been confirmed in numerous clinical trials. For example, Mori et al. (2009) carried out a placebo-control, parallel-group and double-blind clinical trial on 30 patients with middle cognitive impairment by providing four $250 \mathrm{mg}$ tablets consist of $96 \%$ mushroom powder or placebo thrice a day up to 16 weeks, continued the trial up to four weeks and assessed using a cognitive function scale by Revised Hasegawa Dementia Scale (HDS-R). On comparison to the placebo group (weeks 8, 12, and 16) treatment and four weeks of follow-up, the yamabushitake group revealed significantly increased scores. However, in the fourth week, at the end of ingestion the values significantly decreased. However, H. erinaceus has proved to be valuable in the improvement of average cognitive impairment.

Hericium erinaceus stopped the impairments of visual recognition and spatial short-term memory because of induction by A $\beta 25-35$ peptide administered in mice intracerebroventricularly (Mori et al. 2011). Owing to the effect of H. erinaceus on the brain function as well as autonomic nervous, Nagano et al. (2010) studied the impacts on menopause, depression, sleep quality, and undefined disorders (randomized, double-blind, placebo-controlled trials). Assessments were carried out based on the Kupperman Menopausal Index (KMI), the Pittsburgh Sleep Quality Index (PSQI), the Center for Epidemiologic Studies Depression Scale (CES-D), and the Indefinite Complaints Index (ICI). A group of 30 females was randomly allotted to consume either cookies four H. erinaceus ( $0.5 \mathrm{~g}$ powder carpophore/cookie) or four placebo cookies once a day up to one month. In the treated group, after the HE intake, the CES-D and ICI scores significantly lowered than before, on comparison with the placebo group, the "insensitive" and "palpitation" terms of the ICI were substantially lower, and the terms "concentration", "irritating", and "anxious" tended to be lower. This study showed that $H$. erinaceus is capable to alleviate the anxiety and depression (Nagano et al. 2010).

Supplementation with erinacine A-enriched $H$. erinaceus mycelia extended the lifespan in both Drosophila melanogaster and SAMP8 mice by a maximum of $32 \%$ and $23 \%$, respectively, compared to the untreated controls. Moreover, erinacine A-enriched H. erinaceus mycelia decreased TBARS levels and induced the antioxidative enzyme activities of superoxide dismutase, catalase, and glutathione peroxidase ( $\mathrm{Li}$ et al. 2019). 


\section{Anticancer/antitumor activities}

Cancer is the second most significant cause of human mortality across the globe, which was the reason for almost 10 million cancer deaths during 2020 (Sung et al. 2021). Extended protocols of treatment and the severe side effects of the current anticancer drugs demand an urgent need to explore safe and effective drugs. Mushrooms are important source of novel metabolites with unique structural and functional traits with potent cytotoxicity. Recently, various structurally of bioactive metabolites have been identified from Hericium and assessed for their anticancer potential. Bioactive metabolites of Hericiumm also serve as lead molecules for the pharmacological industry to develop new drugs. Here we summarize the anticancer impacts of natural products derived from H. erinaceus.

The extract obtained from $H$. erinaceus displayed various biological activities including anticancer one (Li et al. 2014a). Erinacine A-enriched H. erinaceus mycelia was found to be active against the ischemic stroke, as it reduces the neuronal apoptosis plus the size of the stroke cavity in brain by aiming iNOS/reactive nitrogen species (RNS) and p38 mitogen-activated protein kinase (MAPK)/CCAAT enhancer-binding protein homologous protein (CHOP) pathways (Li et al. 2018).

Novel cytotoxic phenols are known as hericenone A (1) and B (2) (Fig. 1) were obtained from the mushroom $H$. erinaceus. The minimum concentrations lead to complete inhibition of growth of HeLa cells for hericenone A (1) was $100 \mu \mathrm{g} / \mathrm{mL}$, for hericenone B (2) was $6.3 \mu \mathrm{g} / \mathrm{mL}$, the potent cytotoxicity of (2) may be due to $\gamma$-1actam and its N-substituent (Kawagishi et al. 1990). Novel $\gamma$-pyrones, erinapyrones A (43), and B (44) (Fig. 3) have been isolated from the culture-broth of $H$. erinaceus mycelia. The compound $(\mathbf{4 3})$ and $(\mathbf{4 4})$ exhibited cytotoxicity against HeLa cells minimum concentration giving complete death of the cells for (43) was 0.88 and for (44) was 1.76 mM (Kawagishi et al. 1992).

Aromatic compound hericenone L (45) (Fig. 3), isolated from the fruit bodies of H. rinaceum and displayed cytotoxic activity against the EC109 cell line with an $\mathrm{IC}_{50}$ of $46 \mu \mathrm{g} / \mathrm{mL}$ (Ma et al. 2012). A new isoindolinone alkaloid named isohericenone (46), together with compounds, namely isohericerin (47), erinacerin A (48), 3,4-dihydro-5-methoxy-2-methyl-2-(4'-methyl-2'-oxo-3'pentenyl)-9(7H)-oxo-2H-furo[3,4-h]benzopyran $(33)$, were extracted from the semi dried fruit bodies of $H$. erinaceus. The compound (46) displayed the potent cytotoxic activity with $\mathrm{IC}_{50}$ values of 2.6, 3.1, 1.9, and $2.9 \mu \mathrm{M}$ against A549, SK-OV-3, SK-MEL-2, and HCT-15 cell lines, respectively. The compound (47) showed cytotoxic activity against A549, SK-OV-3, SK-MEL-2, and HCT-15 cell lines ( $\mathrm{IC}_{50}$ values of $21,8.9,3.1$, and $19 \mu \mathrm{M}$, respectively). The compound (33) was found to be active against A549, SK-OV-3, SK-MEL-2, and HCT-15 cell lines (IC 50 values of $17,11,13$, and $16 \mu \mathrm{M}$, respectively). The compound (48) showed toxicity against A549, SK-OV-3, SK-MEL-2, and HCT-15 cell lines ( $\mathrm{IC}_{50}$ values of $11,11,7.7$, and $14 \mu \mathrm{M}$, respectively). Doxorubicin a positive control displayed cytotoxicity against A549, SK-OV-3, SK-MEL-2, and HCT-15 cell lines ( $\mathrm{IC}_{50}$ values of $0.001,0.003,0.002$, and $0.081 \mu \mathrm{M}$, respectively) (Kim et al. 2012).

A new diterpene (49) (Fig. 3), was isolated from the fungal mycelia of H. erinaceus and displayed good cytotoxicity against K562, LANCAP, HEP2 cancer cell lines with I IC 50 values of 124.5, 362.3 and 198.6 $\mu \mathrm{M}$, respectively. Positive control fluorouracil displayed cytotoxicity against K562, LANCAP, HEP2 cell lines with $\mathrm{IC}_{50}$ values of $76.9,61.5$, and $38.5 \mu \mathrm{M}$, respectively (Zhang et al. 2015a). Compounds (E)-5-(3,7-dimethylocta-2,6-dien-1-yl)-4-hydroxy-6-methoxy-2phenethylisoindolin-1-one (50), was purified from the solid culture of $H$. erinaceus. The compound (50) also showed poor cytotoxic activity against A549 and HeLa, cells ( $\mathrm{IC}_{50}$ values of 49.0 and $40.5 \mu \mathrm{M}$, respectively) (Wang et al. 2015a).

New alkaloids, erinacerin $\mathrm{M}(\mathbf{5 1})$, erinacerin $\mathrm{N}(\mathbf{5 2})$ (Fig. 3), erinacerin $\mathrm{O}(\mathbf{5 3})$, erinacerin $\mathrm{P}$ (54) (Fig. 4), were extracted from the solid cultures of $H$. erinaceus. The compounds $(\mathbf{5 1}-\mathbf{5 4})$ showed moderate cytotoxicity against wild K562 cells with the $\mathrm{IC}_{50}$ values of 16.3, 18.2, 15.9, and $11.4 \mu \mathrm{M}$, respectively (adriamycin as positive control, $\mathrm{IC}_{50}=0.6 \mu \mathrm{M}$ ) (Wang et al. 2015b). Later erinacerin $\mathrm{O}(\mathbf{5 3})$ and erinacerin $\mathrm{P}(\mathbf{5 4})$, were also isolated from $H$. erinaceus. The compound erinacerin $\mathrm{P}(\mathbf{5 4})$ displayed good cytotoxic activity against human glioma cell line U87 with an $\mathrm{IC}_{50}$ 
value of $19.32 \mu \mathrm{g} / \mathrm{mL}$. It was observed that the apoptosis of U87 cells treated with (54) increased, and the morphology of U87 cells altered significantly. Erinacerin P (54) increases the rate of apoptosis rate of U87 cells through Bax/capase-3 pathway and reduces DNA replication. (Zhang et al. 2020).

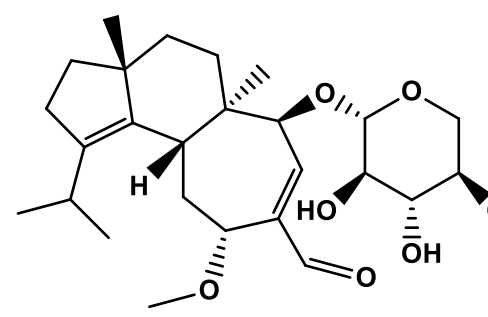

Erinacine Z1 (35)

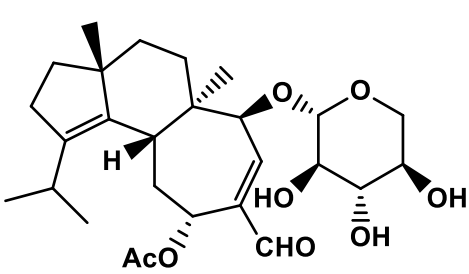

Erinacine $P(40)$

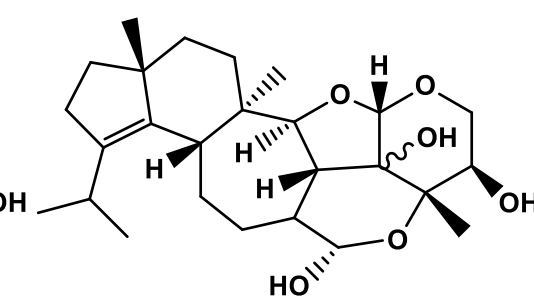

HO" CJ14.258 (36)

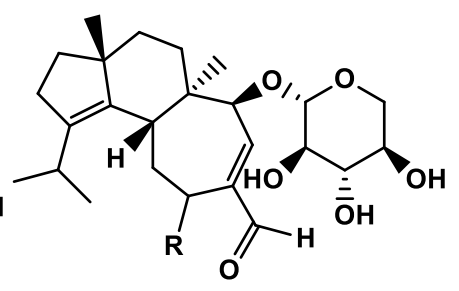

$\mathrm{R}=\mathrm{a}$ OH, Erinacine $\mathrm{T}(\mathbf{3 7})$

$\mathrm{R}=\mathrm{a} \mathrm{OCH}_{3}$, Erinacine $\mathrm{U}(\mathbf{3 8})$

R-b OAc, Erinacine V (39)

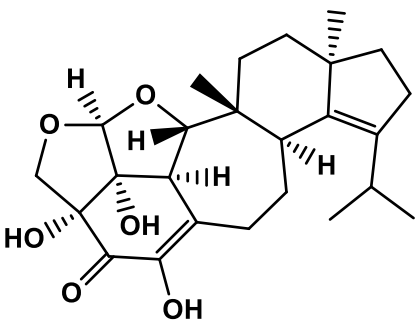

Erinacine S (41)

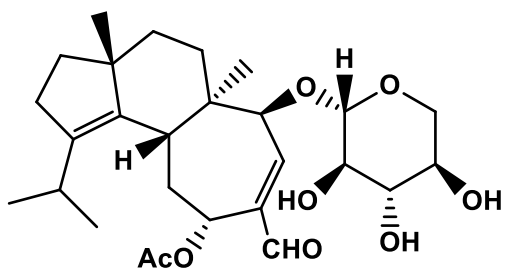

Erinacine R (42)<smiles>CC1=CC(=O)C[C@@H](CO)O1</smiles>

Erinapyrone A (43)

Erinapyrone B (44)<smiles>[R]Cc1cc(OC)c(C/C=C(\C)CC(=O)C=C(C)C)c(O)c1C(=O)O</smiles>

$\mathrm{R}=-\stackrel{1 "}{\mathrm{CO}}\left(\mathrm{CH}_{2}\right)_{14} \stackrel{16 "}{\mathrm{CH}_{3}}$, Hericenones $\mathrm{L}$ (45)<smiles>COc1cc2c(c(O)c1C/C=C(\C)CC(=O)C=C(C)C)CN(CCc1ccccc1)C2=O</smiles><smiles>CCCCCC1(CC(=O)C=C(C)C)CCC2=C(C1)c1cc(OC)c(OC)cc1C2=O</smiles>

Erinacerin A (48)<smiles>COc1cc2c(c(O)c1C/C=C(\C)CCC=C(C)C)CN(CCc1ccccc1)C2=O</smiles>

(E)-5-(3,7-dimethylocta-2,6-dien-1-yl)-4-hydroxy -6-methoxy-2-phenethylisoindolin -1-one (50)<smiles>COc1cc2c(c(O)c1C/C=C(\C)CCC=C(C)C)CN(CCc1ccccc1)C2=O</smiles>

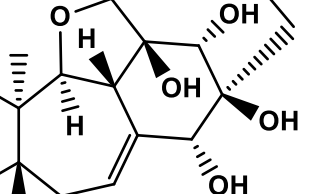<smiles>CC(=O)c1c[nH]c(O)cc1=O</smiles><smiles>CC(=O)c1cn2c(cc1=O)COC(=O)[C@H]2C(C)C</smiles>

Erinacerin M (51),

Fig. 3 - Cytotoxic compounds isolated from Hericium erinaceus.

Two new aromatic compounds, hericerin A (55) and isohericenone $\mathbf{J}(\mathbf{5 6})$, along with five known compounds, isoericerin (57), hericerin (58), N-De phenylethyl isohericerin (59), hericenone J (10), and 4-[3',7'-dimethyl-2',6'-octadienyl]-2-formyl-3-hydroxy-5-methyoxybenzylalcohol (60), 
were obtained from a methanol extract of the fruiting bodies of $H$. erinaceus. The compounds (10, 55-60) displayed cytotoxicity against HL-60 cell lines with $\mathrm{IC}_{50}$ of 4.13, 3.06, 59.74, 5.47, 62.24, 4.10, and $4.28 \mu \mathrm{M}$, respectively (positive control Mitoxantrone $\left.\mathrm{IC}_{50} 0.075 \mu \mathrm{M}\right)$. The compound (10, 55, 56, 60) displayed cytotoxicity against HEL-299 cell lines with $\mathrm{IC}_{50}$ of 5.07, 64.61, 5.79, and $8.46 \mu \mathrm{M}$, respectively. The compounds (55) and (58) also induced apoptosis of HL-60 cells along with time-dependent downregulation of c-myc and p-AKT levels (Li et al. 2015a). Two purified compounds, 1-(5-chloro-2-hydroxyphenyl)-3-methyl-1-butanone (61) and 2,5bis(methoxycarbonyl)terephthalic acid (62), were obtained from the ethanoic extract of fruit bodies of $H$. erinaceus and displayed weak cytotoxicity against $\mathrm{K} 562$ with $\mathrm{IC}_{50}<200 \mathrm{mM}$ (Liu et al. 2016).

Five new isoindolinones named erinaceolactams A-E (63-67) (Fig. 4), together with five known compounds hericenone A (1), hericenone J (10), erinacerin A (48), hericerin (58), and N-De phenylethyl isohericerin (59) were purified from the fruit bodies of $H$. erinaceus extracted in $70 \%$ ethanol. These compounds $(\mathbf{1}, \mathbf{1 0}, \mathbf{5 9}, \mathbf{4 8}, \mathbf{5 8}, \mathbf{6 3}-\mathbf{6 7})$ exhibited significant cytotoxicity against SMMC-7221 comparable to or more potent than 5-FU. Some compounds $(\mathbf{1}, \mathbf{1 0}, \mathbf{4 8 ,} \mathbf{6 3}, \mathbf{6 5}-\mathbf{6 7})$ serve as growth inhibitors of SMMC-7221 in a dose-dependent manner. In MHCC-97H, compounds $(\mathbf{1}, \mathbf{5 9}, \mathbf{6 7})$, inhibited the cell growth dose-dependently. Among these compounds (1, 10, 59, 48, 58, 63-67), compound (1) $(20 \mu \mathrm{g} / \mathrm{mL})$ showed the most potent activity against the growth of SMMC-7221 and MHCC-97H (Wang et al. 2016).

A new cyathane-type diterpenoids, hericinoid B (68) and known analogues erinacine Z2 (69) (Fig. 4), erinacine Z1 (35), were isolated from fermentation broth of $H$. erinaceus. The compounds $(68,35$, and 69) displayed potent cytotoxicity against HL-60 cell lines with the IC 50 values of 18.3, 8.9 , and $0.5 \mu \mathrm{M}$, respectively. The compounds (35) and (69) showed moderate cytotoxicity against MCF-7 cell lines with the $\mathrm{IC}_{50}$ values from 13.4 to $15.8 \mu \mathrm{M}$. Cisplatin as positive control showed cytotoxic activity towards HL-60 MCF-7 cells (with $\mathrm{IC}_{50}$ value of 2.8 and $27.7 \mu \mathrm{M}$, respectively), while paclitaxel as another positive control showed cytotoxic activity towards HL-60 MCF-7 cells ( $\mathrm{IC}_{50}$ of $<0.008 \mu \mathrm{M}$ each) (Chen et al. 2018).

A known cyathane diterpene erinacine A (17) was isolated from the liquid cultures of $H$. erinaceus and displayed weak cytotoxicity against PC12 cells ( $\mathrm{IC}_{50}$ of $73.7 \mu \mathrm{M}$ ) (Zhang et al. 2018). Known compounds ergosteryl stearate (70), ergosterol peroxide (71) (Fig. 5), and hericenone I (9) were isolated from the fruiting bodies of the medicinal mushroom $\mathrm{H}$. erinaceus. The compound (9) displayed potent cytotoxic activity against SH-SY5Y, 1321N1, HCT-116, Caco2, OVK18, and HeLa cell lines with $\mathrm{IC}_{50}$ values of $36.69,41.66,7.66,49.53,0.99$, and $25.94 \mu \mathrm{M}$, respectively. The compound (71) displayed potent cytotoxic activity against SH-SY5Y, 1321N1, HCT-116, Caco-2, OVK18, and HeLa cell lines with $\mathrm{IC}_{50}$ values of 10 8.84, 21.68, 52.73, 6.35, 8.07, and $33.04 \mu \mathrm{M}$, respectively. The compound (70) displayed selective cytotoxic activity against SH-SY5Y, HCT-116, and OVK18 cell lines ( IC $_{50}$ values of 35.52, 2.77, and $8.1 \mu \mathrm{M}$, respectively) (Ashour et al. 2019).

The peptide Lys-Ser-Pro-Leu-Tyr (KSPLY) was derived from H. erinaceus, its synthetic peptide showed potential immunomodulatory activity at $100 \mu \mathrm{mol} / \mathrm{l}$ and also promoted NO, IL-1 $\beta$, IL-6 and TNF- $\alpha$ secretion of by the macrophages. The KSPLY also inhibited secretion of nitric oxide (NO) as well as IL-6 by the M1 macrophages with a tendency of transformation of macrophages M2 macrophages into M1. This peptide is an effective immunomodulation seems to be beneficial to combat human cancer (Yu et al. 2021).

A study by Tung et al. (2021) indicated that erinacine S (41) specifically induces cell apoptosis and increased ROS production in gastric cancer cells only. The normal cells are not affected. Erinacine S (41) also suppressed tumor growth in a xenograft mouse model. Furthermore, erinacine $S$ (41) treatment significantly increases the FasL and tumor necrosis factor-related apoptosis-inducing ligand (TRAIL) protein. In contrast, it also decreased the levels of PCNA as well as cyclin D1 in the gastric cancer xenograft in mice. In human gastric epithelial cell line (AGS) the erinacine S (41) triggers the apoptosis pathways (TRAIL, Fas-L and caspase-8, -9, -3) as well as suppresses the expression of the antiapoptotic molecules like Bcl-2 and Bcl-XL. Besides, erinacine S (41) causes arrest of cell cycle phase G1 via inactivation of CDKs/cyclins. The data 
also revealed that activation of AKT/FAK/PAK1 and ROS-derived pathways involved in the erinacine S-mediated transcriptional activation of Fas-L and TRAIL by H3K4 trimethylation on their promoters (Tung et al. 2021).

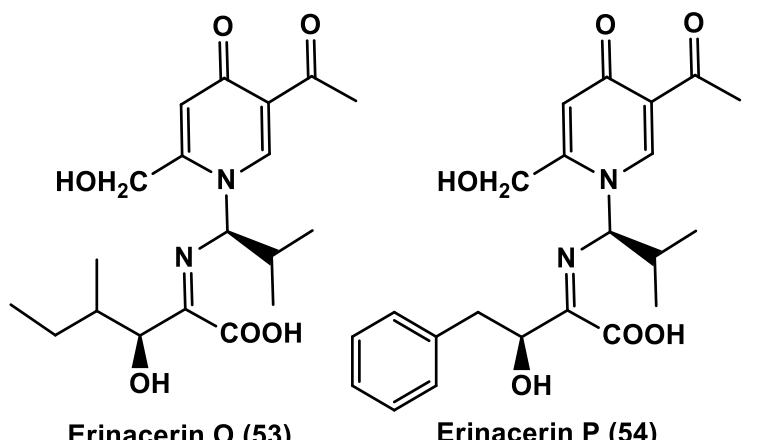

Erinacerin $\mathrm{O}(53)$<smiles>COc1cc2c(c(O)c1C/C=C(\C)CCC=C(C)C)CN(CCc1ccccc1)C2=O</smiles>
Isoericerin (57)<smiles>COc1cc2c(c(O)c1C/C=C(\C)CCC=C(C)C)CNC2=O</smiles>

N-De phenylethyl isohericerin (59)<smiles>CC(C)CC(=O)c1cc(Cl)ccc1O</smiles>

1-(5-chloro-2-hydroxyphenyl) -3-methyl-1-butanone) (61)<smiles>COC(=O)c1cc(C(=O)O)c(C(=O)O)cc1C(=O)O</smiles>

2,5-bis(methoxycarbonyl) terephthalic acid (62)<smiles>COc1cc2c(c(O)c1C/C=C(\C)CCC=C(C)C)CN(CCO)C2=O</smiles>

Hericerin A (55)<smiles>COc1cc2c(c(O)c1C/C=C(\C)CCC=C(C)C)COC2=O</smiles>

Isohericenone J (56)<smiles>COc1cc2c(c(O)c1C/C=C(\C)CCC=C(C)C)C(=O)N(CCc1ccccc1)C2</smiles>

Hericerin (58)<smiles>COc1cc(O)c(C=O)c(O)c1C/C=C(\C)CCC=C(C)C</smiles>

4-[3', 7'-dimethyl-2', 6'-octadienyl]2-formyl-3-hydroxy-5 -methyoxybenzylalcohol (60)<smiles>COc1cc2c(c(O)c1C/C=C(\C)CC(=O)C=C(C)C)CNC2=O</smiles>

Erinaceolactam A (63)<smiles>CCCCC(=O)CC1(C)CCc2c(OC)cc3c(c2O1)CNC3=O</smiles>

Erinaceolactam B (2)(64)<smiles>COc1cc2c(c(O)c1C/C=C(\C)CC(=O)C=C(C)C)CN(CCO)C2=O</smiles>

Erinaceolactam C (65)

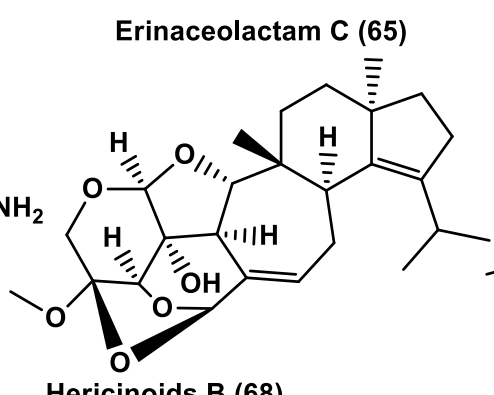

Hericinoids B (68)<smiles>COc1cc2c(c3c1CCC(C)(CC(=O)C=C(C)N)O3)CN(CCO)C2=O</smiles>

Erinaceolactam D (66)<smiles>COc1cc2c(c3c1CCC(C)(CC(=O)C=C(C)C)O3)CN(CCCC(N)=O)C2=O</smiles>

Erinaceolactam E (67)

.

Fig. 4 - Cytotoxic compounds isolated from Hericium erinaceus (cont.).

The microwave-assisted extraction in 50\% ethanol, hot water extract (HWE), acidic as well as alkaline extracts of the fruit body of $H$. erinaceus showed the apoptotic ability against the U937 human monocytic leukemia cells. Assays like cell viability, cytotoxicity, chromosomal DNA 
integrity, and expression of pro- and anti-apoptotic proteins, mitochondrial membrane potential and activation and inhibition of caspase assays were performed to define the mechanism of apoptosis. The aqueous as well as aqueous/ethanolic extracts were active these assays, whereas the acidic and alkaline extracts were inactive. The results of the bioassays showed activation of mitochondriamediated the caspase- 3 and caspase- 9 but not the caspase- 8 (Kim et al. 2011). Erinacine A (17) also exhibited significant antitumor activity against TSGH 9201 cancer cell lines. It induced apoptosis in association with increased phosphorylation of focal adhesion kinase/protein kinase FAK/Akt/p70S6K as well as serine/threonine kinase PAK-1 pathways. It also involved in increase of cytotoxicity, increase of ROS generation, reduction of invasiveness, activation of caspases, and expression of tumor necrosis receptor (TRAIL) (Kuo et al. 2017).

Erinacine $\mathrm{A}$ is one of the major bioactive diterpenoids extracted from cultured mycelia of $H$. erinaceus, which displays pronounced antitumorigenic activities. An in vitro study on two human colon cancer cell lines: DLD-1 and HCT-116 showed that erinacine A stimulates the extrinsic apoptosis activation pathways (TNFR, Fas, FasL and caspases) and decreases the levels of antiapoptotic molecules Bcl-2 and Bcl-XL, suppresses of phosphorylation of Jun N-terminal kinase JNK1/2 and responsive to stress stimuli (NF-KB p50 and p330). The in vivo assay showed that Erinacine A increases the levels of histone H3K9K14ac, histone acetylation on Fas and FasL including TNFR promoters (Lee et al. 2019).

Anticancer effect of extracts (HTJ5 and HTJ5A) obtained from the broth of $H$. erinaceus was evaluated against many cancers by in vitro cancer cell lines and in vivo tumor xenografts (e.g. gastrointestinal cancers: liver, colorectal and gastric). The H. erinaceus extracts HTJ5 and HTJ5A displayed cytotoxic activity against the liver (HepG2 and Huh-7), colon (HT-29), and gastric (NCI87) cancer cells. In in vivo tumor xenograft studies, the HTJ5 and HTJ5A exhibited significant antitumor activity against the four xenograft models (HepG2, Huh-7, HT-29, and NCI-87) without the host toxicity. In addition, the HTJ5 and HTJ5A showed higher effect compared to the 5-FU against the above-mentioned tumors with less toxicity. A total of 22 compounds were fetchd from the fractions of HTJ5/HTJ5A with seven cyclic dipeptides, six small aromatic compounds, five indole, three flavones, one anthraquinone, pyrimidines and amino acids derivatives. These compounds include seven cyclic dipeptides: cyclo(Val-Tyr), cyclo(Leu-Tyr), cyclo(Phe-Tyr), cyclo(Phe-Phe), cyclo(Leu-Leu), cyclo(Leu-Ala), and cyclo(Val-Ala); five indole, pyrimidines, amino acids and derivative: 5-hydroxy-2-pyridinecarboxylic acid, 3-formylindole, uracil, 2,3,4,9tetrahydro-1Hpyrido[3,4-b]indole-3-carboxylic acid, and tryptophan; three flavones (flavonoid glycoside): neoliquirtin, liquiritigenin, and calycosin; one anthraquinone: emodin; and six small aromatic compounds: 4-hydroxy-3-methoxybenzoic acid, 4-hydroxy-3-methoxycinnamic acid, hydroxy-benzaldehyde, 4-hydroxybenzoic acid, 3,4-dihydroxybenzaldehyde and syringic acid (Li et al. 2014a).

\section{Anticarcinogenic effects}

An anticarcinogen is a carcinopreventive agent that counteracts the effects of a carcinogen on normal cells and inhibits the development of cancer. Extract from $H$. erinaceus or bioactive from H. erinaceus possess anticarcinogenic effects, and some of them are illustrated below.

The mutagenicity and genotoxicity effects of erinacine A-enriched $H$. erinaceus (EAHE) mycelium were evaluated by in three standard tests (chromosomal aberration, micronuclei tests and reverse mutation). The results showed that the EAHE mycelium has not increased the number of revertant colonies in bacterial reverse mutation and not induced higher frequency of aberrations. In addition, there was no significant EAHE mycelium-induced increase was seen in the incidence of reticulocytes per $1000 \mathrm{RBC}$ as well as micronucleus per 1000 reticulocytes. All these three standard tests suggested lack of mutagenicity and genotoxicity of EAHE mycelium at test doses under standard experimental conditions ( $\mathrm{Li}$ et al. 2014b). Glycosphingolipid (monoglycosylceramides cerebroside E) (72), is a new cerebroside isolated from the fruit bodies of H. erinaceus (Fig. 5). This has alleviated cisplatin-induced nephrotoxicity (in LLC-PK1 cells) as well as inhibited the angiogenesis in HUVECs (Lee et al. 2015). 
The $H$. erinaceus has been showed a protective effect on cell death of ischemia-injury-induced neurons in rats. It has been demonstrated that pretreatment with $H$. erinaceus attenuated the DEHPinduced cell death significantly. Such protective effect may be owing to its ability to reduce the intracellular levels of ROC species, which preserves the activity of respiratory complexes to stabilize the potential of mitochondrial membrane. In addition, $H$. erinaceus pre-treatment has modulated Nrf2 and Nrf2-dependent vitagenes expression significantly, thus prevents rise of proapoptotic and the fall of antiapoptotic markers. Overall, the present study provided evidence towards new preventive nutritional strategy by $H$. erinaceus over DEHP-induced apoptosis (PC12 cells) (Amara et al. 2020).
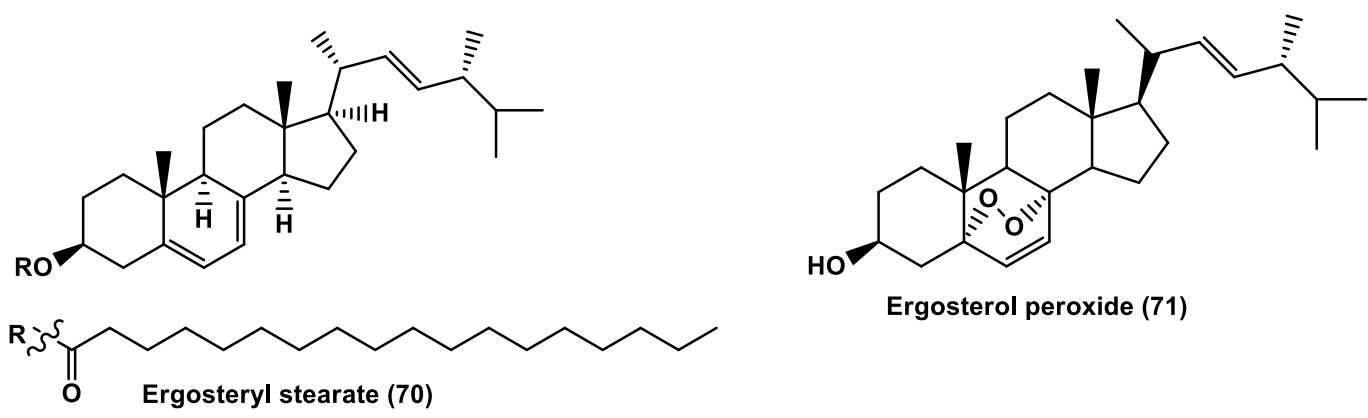

Ergosterol peroxide (71)<smiles>CCCCCCCCCCCCCCCCC[C@H](O)C(=O)N[C@H](CO[C@H]1O[C@H](CO)[C@@H](O)[C@H](O)[C@H]1O)[C@H](O)/C=C/CC/C=C(\C)CCCCCCC</smiles>

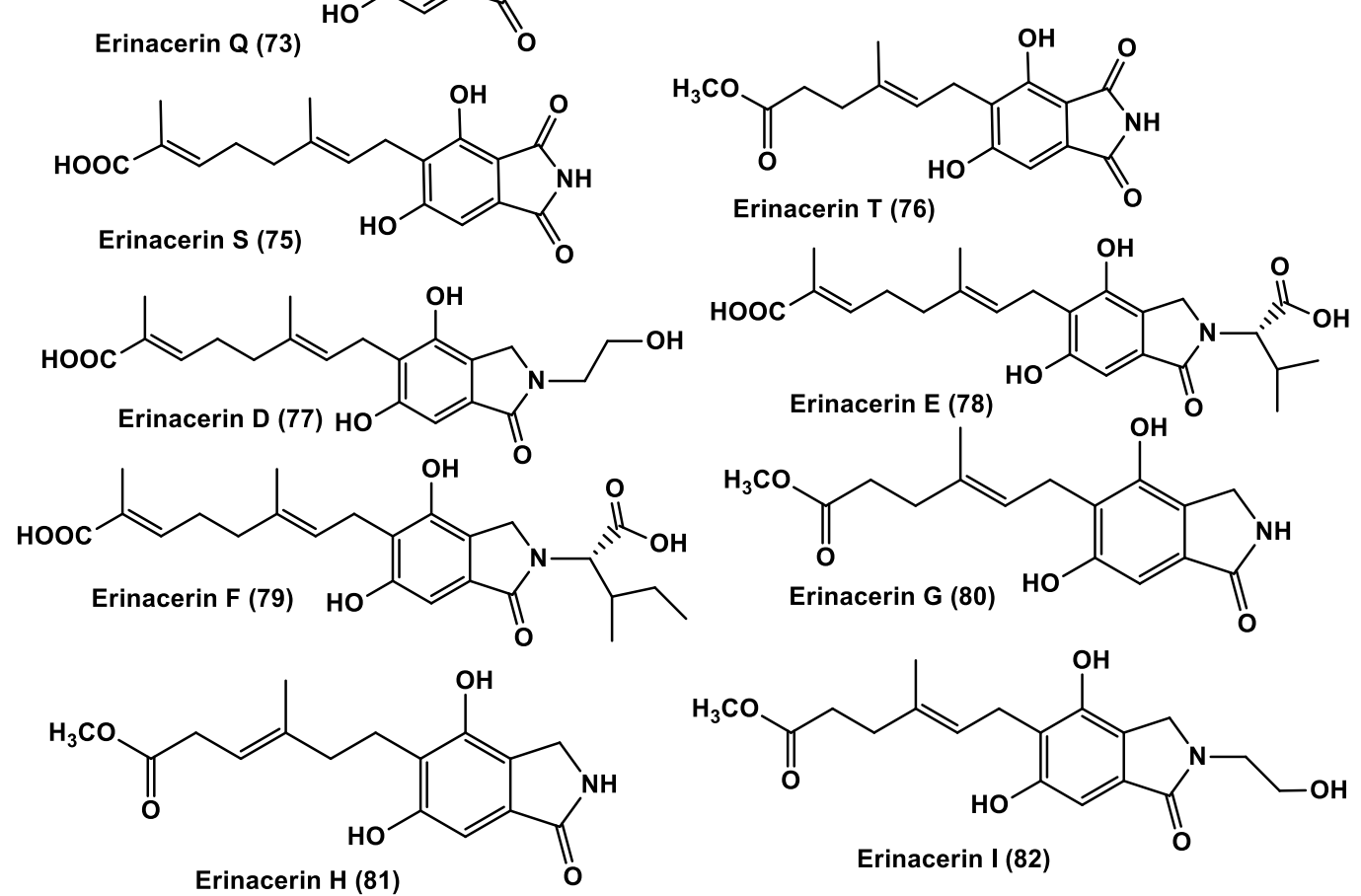

Fig. 5 - Cytotoxic compounds isolated from Hericium erinaceus (cont.).

The H. erinaceus mycelium-enriched erinacine A $(5 \mathrm{mg} / \mathrm{g})$ toxicity by a 28 -day oral administration using Sprague-Dawley rats at three doses (low, $1 \mathrm{~g}$; medium, $2 \mathrm{~g}$; high $3 \mathrm{~g} / \mathrm{kg}$ body 
weight/day) were selected with distilled water as control showed survival of all the animals till end of the study. No abnormality in clinical signs were observed without adverse differences were found in haematology, serum biochemical parameters and urinalysis among the control and treated groups. Similarly, pathologically and histopathological manner, no gross changes were evident. Thus, the EAHE at $3 \mathrm{~g} / \mathrm{kg}$ body weight/day has no adverse effects on test Sprague-Dawley rats ( $\mathrm{Li}$ et al. 2014c).

\section{Antidiabetic Activity (Alpha-glucosidase inhibitors)}

Diabetes mellitus (DM) is one of the rapidly growing lifestyle disorders of $21^{\text {st }}$ century, affecting the health of significant population worldwide. According to recent statistical studies, it is estimated that about 415 million people across the world are presently suffering from diabetes (Ogurtsova et al. 2017). Some of the compounds isolated from H. erinaceus possess antidiabetic properties and are illustrated below.

New alkaloids, erinacerins Q (73), R (74), S (75), and T (76), were purified from the cultures of $H$. erinaceus (Fig. 5). These compounds (73-76) showed inhibitory activities against PTP1B with $\mathrm{IC}_{50}$ values of $29.1,42.1,28.5$, and $24.9 \mu \mathrm{M}$, respectively (positive control, sodium vanadate $\left.\mathrm{IC}_{50}=1.2 \mu \mathrm{M}\right)$. The compounds (73-76) showed inhibitory activities against a-glucosidase inhibition with $\mathrm{IC}_{50}$ values of $12.7,23.3,19.5$, and $20.1 \mu \mathrm{M}$, respectively (positive control, acarbose $\mathrm{IC}_{50}=273.1 \mu \mathrm{M}$ ) (Wang et al. 2015b).

New compounds isoindolin-1-ones designated as erinacerins D-L (77-85) along with (E)-5( 3,7-dimethylocta-2,6-dien-1-yl) -4-hydroxy-6-methoxy-2-phenethylisoindolin-1-one ( 50) were obtained from the cultures of $H$. erinaceus. These compounds $(\mathbf{5 0 , 7 7 - 8 5 )}$ showed inhibitory effect at $\mathrm{IC}_{50}$ ranging from 5.3-145.1 $\mu \mathrm{M}$ in $\alpha$-glucosidase inhibition assay (Fig. 6). The structure-activity relationship indicated that the presence of terpenoid side chain and phenolic hydroxy groups are conducive for the $\alpha$-glucosidase inhibitory activity of $\mathbf{5 0}$ and 77-85) (Wang et al. 2015a).

Four new compounds, erinacenol D (86), together with known compounds 4-[3',7'-dimethyl2',6'-octadienyl]-2-formyl-3-hydroxy-5-methyoxybenzylalcohol $(\mathbf{8 7})$, hericene A $(\mathbf{8 8})$, hericene D (89), and known compound hericenone D (4) retrieved from the fruit bodies of $H$. erinaceus. These compounds (86-89 and 4) displayed potent $\alpha$-glucosidase inhibitory activity with $\mathrm{IC}_{50}$ 19.6, 7.5, 6.7, 3.9, and $15.5 \mu \mathrm{M}$, respectively ( positive control acarbose, $\mathrm{IC}_{50}, 71.2 \mu \mathrm{M}$ ). The molecular docking showed the interaction of $\alpha$-glucosidase as well as isolated compounds supporting the inhibitory activity against $\alpha$-glucosidase (Lee et al. 2020).

Meroterpenoids hericenes B (90) and hericenones $\mathrm{C}(\mathbf{3}), \mathrm{E}(\mathbf{5}), \mathrm{F}(\mathbf{6}), \mathrm{G}(\mathbf{7})$ were purified from the fruit body of $H$. erinaceus. The most potent inhibitory activities on PNPG (4-Nitrophenyl betaD-galactopyranoside) showed by the compound (7) and sucrose $\left(\mathrm{IC}_{50}\right.$ of 15.2 and $12.6 \mu \mathrm{M}$, respectively). The compound (3) possesses the strongest inhibitory activities on maltose (IC $\mathrm{I}_{50}$ of $15.3 \mu \mathrm{M}$ ), while the positive control acarbose showed $\mathrm{IC}_{50}$ of $38.1,20.5$, and $17.1 \mu \mathrm{M}$ against PNPG, sucrose, and maltose, respectively. The compound (90) led the most potent inhibitory activities on PNPG sucrose maltose (IC 50 of $29.6,29.1$, and $65.5 \mu \mathrm{M}$, respectively). The compound (3) showed the most potent inhibitory activities agaonst PNPG, sucrose and maltose with the $\mathrm{IC}_{50}$ of 21.9, 13.5, and $15.3 \mu \mathrm{M}$, respectively. The compound (5) possesses the strongest inhibitory activities against PNPG, sucrose and maltose with the $\mathrm{IC}_{50}$ of $23.3,42.5,25.5, \mu \mathrm{M}$, respectively. The compound (6) was the most potent inhibitory potential against PNPG sucrose maltose with the $\mathrm{IC}_{50}$ of $45.3,67.1,>100 \mu \mathrm{M}$, respectively. The compound (7) also showed the most potent inhibitory potential against PNPG, sucrose and maltose with the $\mathrm{IC}_{50}$ of $15.2,12.6$ and $33.1 \mu \mathrm{M}$, respectively. The positive control acarbose showed the most robust inhibition against PNPG, sucrose, and maltose with $\mathrm{IC}_{50}$ of $45.3,67.1,>100,38.1,20.5$, and $17.1 \mu \mathrm{M}$, respectively (Chen et al. 2020).

\section{Antioxidant potential}

Antioxidants are the substances that protects the cell organelles by reacting with highly reactive free radicals which are produced during metabolism. Among various natural alternative 
sources, mushrooms are identified as a major source of potent antioxidant compounds (Mishra et al. 2020). Bioactive metabolites from Hericium with antioxidant properties are illustrated below.

Lew et al. (2020) investigated the antioxidant activities of a standardized aqueous extract of H. erinaceus in an in vitro model of FRDA (Friedreich Ataxia) involving L-Buthionine sulfoximine (L-BSO)-induced human dermal fibroblast expressing abnormal expansion of GAA triplet repeat. L-buthionine sulfoximine is an inhibitor of $\gamma$-glutamylcysteine synthetase, which plays a role in GSH biogenesis (Lew et al. 2020).<smiles>COC(=O)C/C=C(\C)CCc1c(O)cc2c(c1O)CN(CCO)C2=O</smiles><smiles>COC(=O)C/C=C(\C)CCc1c(O)cc2c(c1O)CN([C@H](Cc1ccccc1)C(=O)OC)C2=O</smiles>

Erinacerin L (85)<smiles>COc1cc(CO)c(C=O)c(O)c1CC=C(C)CCC=C(C)C</smiles>

4-[3',7'-dimethyl-2',6'-octadienyl]-2-formyl -3-hydroxy-5-methyoxybenzylalcohol (87)<smiles>COc1ccc2c3c([nH]c2c1)[C@H](O)[C@@]1(O)C(=O)N2CCCC2C(=O)N1[C@H]3CC(C)(C)O</smiles>

12ß-Hydroxyverruculogen TR-2 (91)<smiles>CC/C=C\[C@H](O)[C@@H](O)C1=C(C)C(=O)[C@]2(C[C@@](OC)(C(=O)c3ccccc3)NC2=O)O1</smiles>

Pseurotin A (93)<smiles>COC(=O)CC/C(C)=C/Cc1c(O)cc2c(c1O)CN([C@H](Cc1ccccc1)C(=O)OC)C2=O</smiles>

Erinacerin K (84)<smiles>COc1cc2c(c(O)c1C/C=C(\C)C/C=C/C(C)(C)OO)C(=O)OC2</smiles>

Erinacenol D (86)<smiles>[R]C(=O)OCc1cc(OC)c(CC=C(C)CCC=C(C)C)c(O)c1C=O</smiles>

$R=$ Lineoyl, Hericene $D(89)$ R= Oleoyl, Hericene B (90)<smiles>COc1ccc2c3c([nH]c2c1)[C@@H](C=C(C)C)N1C[C@@]3(O)C(=O)N2CCCC2C1=O</smiles>

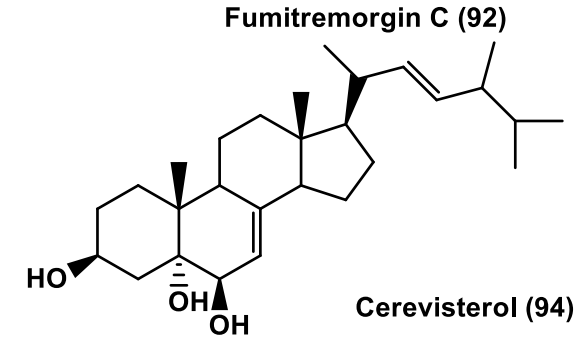

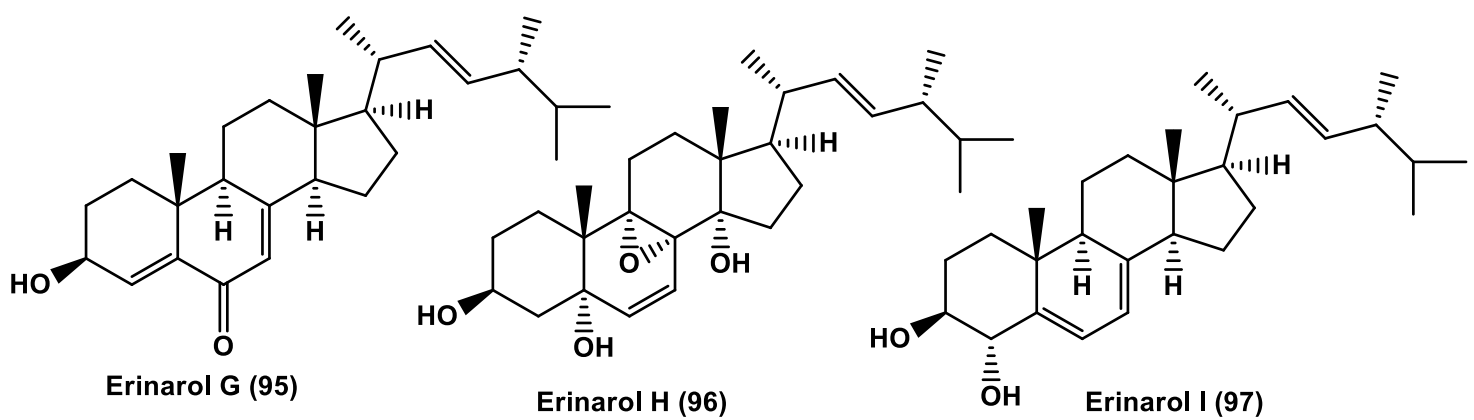

Fig. 6 - Anti-diabetic compounds isolated from Hericium erinaceus. 
Previously reported diketopiperazine alkaloids, 12b-hydroxyverruculogen TR-2 (91), fumitremorgin C (92), and hetero-spirocyclic $\gamma$-lactam alkaloids, pseurotin A (93), and cerevisterol (94) were purified from the mycelium of the H. erinaceus. These compounds (91-94) displayed scavenging activity in DPPH assay with $\mathrm{IC}_{50}$ values of $12.56,50.00,12.56$, and $11.38 \mu \mathrm{M}$, respectively (positive control TBHQ $\mathrm{IC}_{50}, 5.75 \mu \mathrm{M}$, while the ascorbic acid showed IC50, 1.95 $\mu \mathrm{M})$ (Fig. 6). The results indicate that compounds (91, 93, and 94) exhibited better antioxidant activity against in DPPH assay with $\mathrm{IC}_{50}$ of ca. $12 \mu \mathrm{M}$, compared with the tertiary butylhydroquinone as a positive control (Lu et al. 2014).

\section{Anti-inflammatory activity}

Inflammation is one of the protective processes that can become disrupted under pathological conditions. It can lead to many ailments such as multiple sclerosis, rheumatoid arthritis, psoriasis and inflammatory bowel diseases. It also plays a crucial role in many complex disorders like cancer, cardiovascular disease and AD. Many therapies could be followed to treat inflammationdriven ailments such as antihistamines, steroids and non-steroidal anti-inflammatory drugs. In spite of some success, still there is a gap to treat the inflammatory diseases. Various structurally diverse bioactive metabolites are reported from Hericium with the capability to serve as a lead molecule to develop as an anti-inflammatory drug in the future. Here we summarize the anti-inflammatory property of bio-actives from $H$. erinaceus.

Erinacine C (19) is well known for antineuro-inflammatory and neuroprotective functions, which could be accomplished by mechanisms such as inducible nitric oxide synthase (iNOS) protein expression, activation of Nrf2/HO-1 stress-protective pathway and inhibition of I $\mathrm{KB}$, p$\mathrm{I} \kappa \mathrm{B} \alpha$ (involve in the upstream NF- $\kappa \mathrm{B}$ signal transduction cascade) (Wang et al. 2019a). Treating human BV2 microglial cells with lipopolysaccharide (LPS)-induced inflammation caused reduction in levels of many constituents such as: IL-6, TNF- $\alpha$, nitric oxide (NO) and iNOS; expression of the heme oxygenase-1 (HO-1) protein; increased nuclear transcription factor erythroid 2-related factor (Nrf2); inhibition of phosphorylation of $\mathrm{I} \kappa \mathrm{B} \alpha(\mathrm{p}-\mathrm{I} \kappa \mathrm{B} \alpha)$ proteins; inhibition of NF- $\kappa \mathrm{B}$ expression; inhibition of Kelch-like ECH-associated protein 1 (Keap1). Considering these data, the mechanism of action of EC includes: expression of iNOS, activation of the Nrf2/HO-1 pathway and inhibition of $\mathrm{I} \kappa \mathrm{B}, \mathrm{p}-\mathrm{I} \kappa \mathrm{B} \alpha$ (Wang et al. 2019a).

Four new sterols namely erinarol G (95), erinarol H (96) (Fig. 6), erinarol I (97), erinarol J (98), along with known sterols namely (3b,5a,22E)-ergosta-6,8(14),22-triene-3,5-diol (99), fomentarol A (100), (3b,7a,22E)-ergosta-8(14),22-diene-3,7-diol (101), 7-ketobrassicasterol (102), $(3 \mathrm{~b}, 22 \mathrm{E})$ ergosta-5,8(14),22-triene-7-one (103), 5a,6a-epoxy-3b-hydroxy-ergosta-22-ene-7-one (104), 5a,6a-epoxy-(22E,24R)-ergosta-8(14),22-diene-3b,7b-diol (105), 5a,6a-epoxy-(22E,24R)ergosta-7,22-diene-3b-ol (106), 5a,6a;8a,9a-diepoxy-(22E,24R)-ergosta-22-ene-3b-7a-diol (107), and 5a,6a;8a,9a-diepoxy-(22E,24R)-ergosta-22-ene-3b-7b-diol (108) were isolated from a methanol extract of the dried fruiting bodies of $\mathrm{H}$. erinaceus (Fig. 7). Anti-inflammatory functions of these compounds were evaluated towards NO production in LPS-stimulated murine RAW264.7 macrophage cells and inhibition of TNF- $\alpha$. The compounds $(\mathbf{9 6}, \mathbf{9 8 - 1 0 0})$ exhibited inhibitory activity against TNF- $\alpha$ secretion, with inhibition values of $37.5 \%, 43.3 \%, 36.7 \%$, and $33.7 \%$, respectively, at $10 \mu \mathrm{M}$ (positive control Celecoxib, 52.5\% at $1 \mu \mathrm{M}$ ). The compounds $(\mathbf{9 5}, \mathbf{9 7 , 1 0 1}$, and 103) exhibited moderate inhibitory activity of TNF- $\alpha$ secretion with inhibition ranging from 24.6-26.3\% at the same concentration. Compounds $(\mathbf{9 8}, \mathbf{1 0 2}-\mathbf{1 0 4})$, exhibited significant inhibitory effects against NO production, with inhibition values of $38.4 \%, 50.5 \%, 71.5 \%$, and $51.6 \%$, respectively, while at $10 \mu \mathrm{M}$ (positive control Celecoxib, 55.9\% at $1 \mu \mathrm{M}$ ), compounds (99) and (106-109) exhibited moderate inhibitory activities. Only compound (98), which possesses a 6,8dioxabicyclo[3.2.1] oct-2-ene moiety, showed strong inhibition in both the nitric oxide and TNF-a secretion assay (Li et al. 2015b).

Oral $H$. erinaceus treatment showed promising efficacy in the experimental colitis model. Biochemical indexes and microscopic and macroscopic colitis scores were analyzed. The TNF- $\alpha$, MPO, NO, MDA, and IL6 cytokines, which affect TBNS-induced colitis models, were examined, 
and TNF- $\alpha$, MPO, NO, MDA, and IL6 levels were lower in the H. erinaceus treatment group than in the colitis groups. The less mucosal injury was detected in the $H$. erinaceus treatment group than in the colitis group. The results indicate that the improvement of inflammatory bowel disease (IBD) is due to the anti-inflammatory properties of $H$. erinaceus. The main disadvantage of oral therapy with HE is the unknown dose required for the anti-inflammation effect (Durmus et al. 2021).

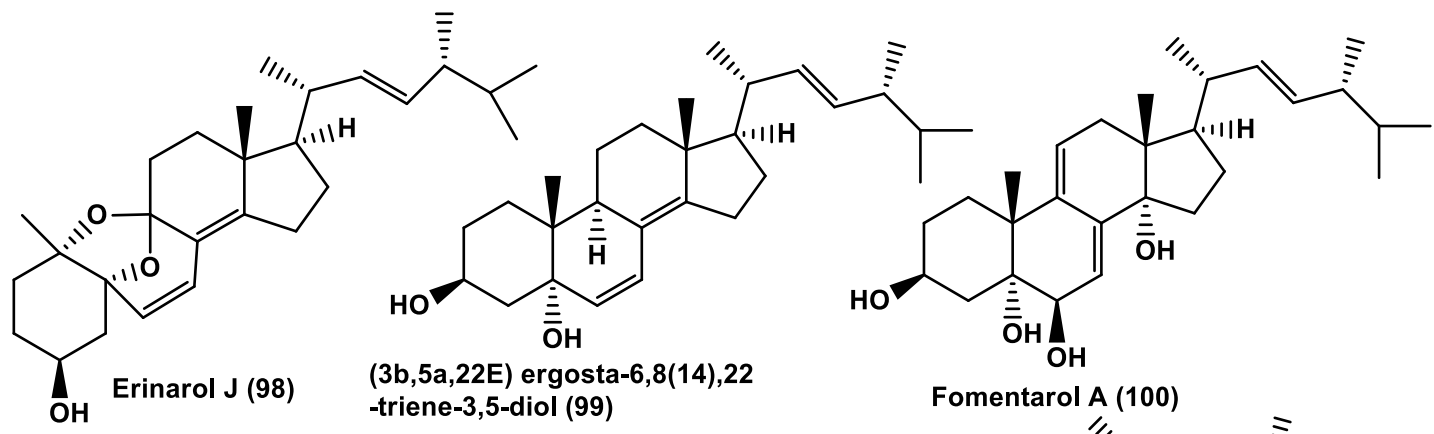

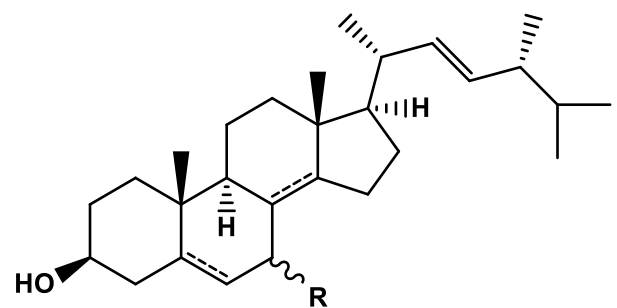

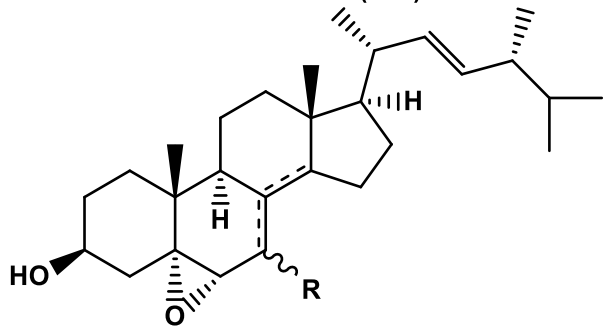
$\mathbf{R}=\mathbf{a}$ OH $\Delta^{8(14)}(\mathbf{3 b}, 7 \mathbf{a}, 22 \mathrm{E})$ ergosta-8(14)
22-diene-3,7-diol (7) (101)
$\mathbf{R}=\mathbf{0} \Delta^{5}$ 7-ketobrassicasterol (8) (102)
$\mathbf{R}=0 \Delta^{5,8(14)}$ (3b,22E) ergosta-5,8(14),
22-triene-I-one (9) (103) 24-R=0 5a,6a-epoxy-3b-hydroxy ergosta-22-ene- 7-one (104)

25- R= bOH $\Delta^{8(14)}$ 5a,6a-epoxy-(22E,24R)-ergosta8(14),22-diene-3b,7b-diol (105)

26- R=H $\Delta^{7}$ 5a,6a-epoxy-(22E,24R)-ergosta- 7,22-diene3b-ol (106)

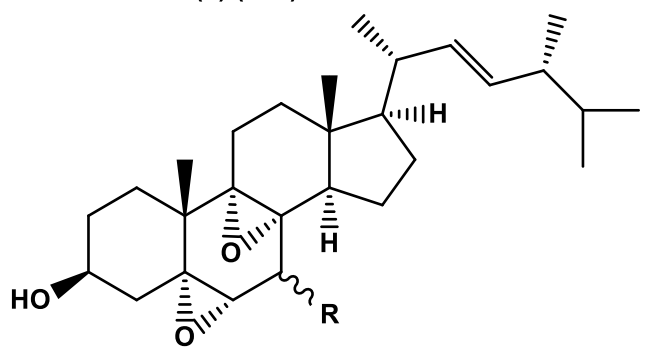

$\mathbf{R}=\mathbf{a}$ OH, 5a,6a;8a,9a-diepoxy-(22E,24R) -ergosta-22-ene-3b-7a-diol (107) $\mathrm{R}=\mathrm{b}$ OH, $5 \mathrm{a}, 6 \mathrm{a} ; 8 \mathrm{a}, 9 \mathrm{a}-$ diepoxy-(22E,24R) -ergosta-22-ene-3b-7b-diol (108)<smiles>COc1ccc(C(=O)O)cc1C(C)=O</smiles>
3-acetyl-4- methoylbenzoic acid (109)<smiles>COc1cc(CO)cc(OC)c1Cl</smiles>

4-Chloro-3,5-dimethoxybenzyl alcohol (111)<smiles>CC(C)CC(=O)c1cc(Cl)ccc1O</smiles>

1-(5-chloro-2-hydroxyphenyl) -3-methyl-1-butanone (1) (112)<smiles>CC(C)CC(=O)c1cc(Cl)ccc1O</smiles>

1-(5-chloro-2- hydroxyphenyl)-3 -methyl-1-butanone (3) (110)<smiles>COC(=O)c1cc(C(=O)O)c(C(=O)O)cc1C(=O)O</smiles>

2,5-bis(methoxycarbonyl) terephthalic acid (2) (113)

Fig. 7 - Antimicrobial compounds isolated from Hericium erinaceus.

Hot water (HE-HWA) and ethanolic (HE-ETH) extracts of $H$. erinaceus were investigated for anti-inflammatory and neuroprotective activities: neurotoxicity of hydrogen peroxide $\left(\mathrm{H}_{2} \mathrm{O}_{2}\right)$ induced in HT22 mouse hippocampal neurons and lipopolysaccharide (LPS)-induced BV2 microglial activation. The HE-ETH revealed a potent neuroprotective action through significant 
increase in the viability of $\mathrm{H}_{2} \mathrm{O}_{2}$-treated neurons. In addition, significant reduction in ROS and improvement in the antioxidant enzyme catalase (CAT) and glutathione (GSH). The HE-ETH showed the capacity to significantly improve the mitochondrial membrane potential (MMP) as well as ATP production, whereas reduction in mitochondrial toxicity, nuclear apoptosis and Bcl-2associated $\mathrm{X}(\mathrm{Bax})$ gene expression. However, some of the functions are not affected: heme oxygenase 1 (HO-1), gene expression of nuclear factor erythroid 2-related factor 2 (Nrf2) and $\mathrm{NAD}(\mathrm{P}) \mathrm{H}$ quinone dehydrogenase 1 (NQO1). The HE-ETH also showed significant reduction in nitric oxide (NO) level in LPS-treated BV2, showed an anti-inflammatory activity in the microglia. Thus, the HE-ETH has the potential towards neuroprotective and anti-inflammatory functions in the neuroglia environment (Kushairi et al. 2019)

\section{Platelet aggregation inhibitor}

Platelet aggregation inhibitors prevent platelet adhesion and subsequently clot formation by interfering different steps on clotting cascade. Platelet aggregation inhibitors are indicated in myocardial infarction, atrial fibrillation, following coronary bypass, angioplasty, and stenting. They are also used prophylactically to prevent myocardial infarction and stroke. The reported compounds isolated from $H$. erinaceus with platelet aggregation inhibitor activity are illustrated below.

Hericenone B (2) was isolated from the ethanolic extract of H. erinaceus. Hericenone B (2) selectively inhibited collagen-induced platelet aggregation however, did not affect the aggregation induced by U46619 (TXA 2 analogue), ADP, thrombin, or adrenaline. Furthermore, hericenone B (2) did not inhibit arachidonic acid- or convulxin (GPVI agonist)-induced platelet aggregation. Therefore, it was suggested that the hericenone B blocks collagen signaling from integrin $\alpha 2 / \beta 1$ to release arachidonic acid (Mori et al. 2010).

\section{Antimicrobial activity}

In the last two decades there is steady rise in the discovery of multidrug resistant bacteria (Penicillin resistant Streptococcus pneumonia, vancomycin-resistant Enterococcus faecium and methicillin-resistant Staphylococcus aureus) (Nannini et al. 2010). Due to acquired resistance, it is cumbersome to diagnose and treat many diseases caused by multidrug resistant bacteria (Dheda et al. 2018). Owing to a few alternatives against the fungal diseases, there is necessity to develop compatible antifungal drugs to facilitate therapies like cancer, bone marrow/organ transplants (Lockhart \& Guarner. 2019). The natural products obtained from Hericium are important sources to tune novel metabolites to facilitate the modern medicine. Following sections deal with some developments of using Hericium-derived antimicrobials.

One new diterpene (49) and new compound 3-acetyl-4-methoylbenzoic acid (109), along with four known compounds 1-(5-chloro-2-hydroxyphenyl)-3-methyl-1-butanone (110) 4-chloro3,5-dimethoxybenzyl alcohol (111) (Fig. 7) isolated from the mycelium of $H$. erinaceus. The compound (110) showed potent antibacterial activity with MIC values 32.5-65 $\mu \mathrm{g} / \mathrm{mL}$, while compound (49) and (109) showed moderate antibacterial activity against the growth of Helicobacter pylori (ATCC43504) (MIC values 50-100 mg/mL), and compound (111) showed poor antibacterial activity with MIC values $62.5-125 \mu \mathrm{g} / \mathrm{mL}$ (Zhang et al. 2015a).

Two compounds, 1-(5-chloro-2-hydroxyphenyl)-3-methyl-1-butanone (112) and 2,5bis(methoxycarbonyl)terephthalic acid (113) isolated from the ethanoic extract of fruit bodies of $H$. erinaceus (Fig. 8). The fruiting bodies of $H$. erinaceus were obtained at Fengxian District, Shanghai, China. The compound (112) displayed anti-Helicobacter pylori activity against $H$. pylori ATCC $43504, H$. pylori SS1, H. pylori $9, H$. pylori $64, H$. pylori $78, H$. pylori $83, H$. pylori $\mathrm{W} 2504$, and $H$. pylori DXF with MIC values in the range of $12.5-50 \mu \mathrm{g} / \mathrm{mL}$. In contrast, the compound (113) was found active against the same set of $H$. pylori strains with minimum inhibitory concentration (MIC) values in the range of $6.25-25 \mu \mathrm{g} / \mathrm{mL}$. Positive control metronidazole displayed anti-Helicobacter pylori activity (range, $0.78-1.5625 \mu \mathrm{g} / \mathrm{mL}$ ), while the other positive control tetracycline displays anti-Helicobacter pylori activity in the range of $0.78-3.125 \mu \mathrm{g} / \mathrm{mL}$ 
against the same set of test strains. Both compounds showed weak cytotoxicity against K562 with $\mathrm{IC}_{50}<200 \mathrm{mM}$ (Liu et al. 2016).<smiles>[R6]c1cc(OC)c(Cl)c(OC)c1</smiles>

(S)-4-ydroxy-2,2 -dimethylchromane-6 -carbaldehyde (117)<smiles>COC(=O)c1ccc2c(c1)[C@H](O)CC(C)(C)O2</smiles>

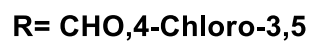
-dimethoxybenzaldehyde (118) $\mathrm{R}=\mathrm{CH}_{3}$, 2-Chloro-1,3-dimethoxy -5-methyl benzene (119) $\mathrm{R}=\mathrm{CH}_{2} \mathrm{OH},(4-\mathrm{Chloro}-3,5$ -dimethoxyphenyl)methanol (120) $\mathrm{R}=\mathrm{COOH}, 3,6-\mathrm{Bis}$ (hydroxyl methyl) $\quad$ 5-Hydroxy-6-(1-hydroxyethyl) -2-methyl-4H-pyran-4-one (121)<smiles>CC(O)c1cc2c(cc1O)COC2=O</smiles>

Erinachromane A (124)<smiles></smiles><smiles>CC(C)CC(=O)c1cc(CO)ccc1O</smiles><smiles>CC(C)=CCc1cc(CO)ccc1O</smiles>

Erinaphenol A (126)

Erinachromane B (125)<smiles>CC1(C)C=Cc2cc(CO)ccc2O1</smiles><smiles>CC1(C)CC(=O)c2cc(CO)ccc2O1</smiles>

Eulatachromene (2,2- dimethyl-6

6-Hydroxymethyl-2,2<smiles>COC(=O)c1ccc(CO)o1</smiles>

4-(Hydroxymethyl)-2-(3-methylbut -2-en-1-yl)phenol (127) -hydroxymethylchromene) (128) -dimethyl-chromanone,<smiles>COc1cc(C=O)cc(OC)c1Cl</smiles><smiles>COC(=O)c1cc(OC)c(Cl)c(OC)c1</smiles>

Methyl 4-chloro-3,5 -dimethoxybenzoate (131) -3-methoxyhexanoic acid (132)

(2S,3R,4S,5R)-2,4,5-Trihydroxy<smiles>C[C@H](O)[C@@H](O)[C@H](O)[C@H](O)C(=O)O</smiles>
2-carboxylate (133)<smiles>CC(=O)Oc1ccc(O)cc1</smiles>

4-Hydroxyphenyl acetate (134)

Fig. 8 - Antimicrobial compounds isolated from Hericium erinaceus.

Known compounds CJ-14,258 (114) and erinacine C (19) isolated from cultured mycelia of H. erinaceus. The compounds (114) and (19) displayed antimicrobial activity against Methicillin- 
resistant Staphylococcus aureus (MRSA) with MIC of $62.5 \mu \mathrm{M}$ each (Kawagishi et al. 2006). A hetero-spirocyclic $\gamma$-lactam alkaloid called FD-838 (115) was isolated from the mycelia of the $H$. erinaceus. Compound (115) inhibited the growth of two phytopathogens (Botrytis cinerea and Glomerella cingulate), with MIC of $6.25 \mu \mathrm{M}$ for each, similar to that of the positive fungicide carbendazim (Lu et al. 2014).

In a growth inhibition assay on six strains $H$. pylori, the ethanolic extracts of $H$. erinaceus showed growth inhibition of all strains with a MIC value of $2 \mathrm{mg} / \mathrm{mL}$. Extract of $\mathrm{H}$. erinaceus inhibited adhesion capacity of (AGS) H. pylori (ATCC CRL-1739). Extract of $H$. erinaceus inhibited adhesion capacity of (AGS) H. pylori (ATCC CRL-1739). Interleukin-8 (IL-8, an immune response factor) in supernatants from AGS and 8-oxo-guanine (8-oxoG, marker for oxidative DNA damage of the total host cell DNA) exposed to $H$. erinaceus extract were monitored prior to addition of $H$. pylori. The result was $H$. pylori-mediated immune response (IL-8 production) significantly decreased by the $H$. erinaceus extract, while at concentration $1.0 \mathrm{mg} / \mathrm{mL}$, the IL-8 expression reversed to almost the background level (when no H. pylori added). Infection of AGS by $H$. pylori resulted in a 3-fold increase of host's 8-oxoG, however such increase was turndown by addition of $2 \mathrm{mg} / \mathrm{mL} \mathrm{H}$. erinaceus extract. Assays were carried out on colonization of C57BL mice on homogenized stomachs three weeks later inoculating $H$. pylori. The mice receiving the $H$. erinaceus extract had a mean $\mathrm{H}$. pylorus at $6 \times 10^{4} \mathrm{CFU} / \mathrm{g}$ in the stomach, which was one log lower than the control (without extract) (Wang et al. 2019b).

The ethyl-acetate extract obtained from culture filtrate and mycelium of $H$. erinaceus displayed potent anti- $H$. pylori activities with MIC (MBC) of $1.25-1.5(5-7.5) \mathrm{mg} / \mathrm{mL}$ and potential urease inhibitory activity with $\mathrm{IC}_{50}$ of $0.34-0.35 \mathrm{mg} / \mathrm{mL}$. The culture filtrate extract also displayed good antioxidant activity $\left(\mathrm{IC}_{50}, 11.83 \mathrm{mg} / \mathrm{mL}\right.$ ), which was marginally better than that of mycelium extract $\left(\mathrm{IC}_{50}, 14.75 \mathrm{mg} / \mathrm{mL}\right)$. It was also found that the water fractions from the culture filtrate and the mycelium exhibited noticeable inhibitory activities against bacterial urease $\left(\mathrm{IC}_{50}\right.$, $1.26-1.40 \mathrm{mg} / \mathrm{mL}$ ). However, they had poor or no anti-H. pylori activities with poor antioxidant activities (Ngan et al. 2021).

Using OSMAC (One Strain, Many Active Compounds approach a new erinacerin alkaloid erinacerin V (116), and a new aldehyde derivative of 4-hydroxy chroman, (S)-4-hydroxy-2,2dimethylchromane-6-carbaldehyde (117), along with four known compounds 4-chloro-3,5dimethoxybenzaldehyde (118), 2-chloro-1,3-dimethoxy-5-methyl benzene (119), (4-chloro-3,5dimethoxyphenyl)methanol (120), 3,6-bis(hydroxyl methyl)-2-methyl-4H-pyran-4-one (121), 4chloro-3,5-dimethoxybenzoic acid (122), 5-hydroxy-6-(1-hydroxyethyl)isobenzofuran-1(3H)-one (123), and erinacine $E$ (21) were isolated from a mycelial culture of Hericium sp. (Fig. 8). Compound (119), exhibited antifungal activity against Candida such as $C$. albicans and $C$. neoformans (MIC, 31.3-62.5 $\mu \mathrm{g} / \mathrm{mL}$, respectively) and also inhibited biofilm formation of $C$. albicans and C. neoformans at $7.8 \mu \mathrm{g} / \mathrm{mL}$ (Song et al. 2020).

The related Basidiomycota Agaricus blazei Murill (AbM), H. erinaceus (HE), and Grifola frondosa (GF) have been shown to exert antimicrobial activity against viral agents, Gram-positive and Gram-negative bacteria, and parasites in vitro and in vivo. Since these basidiomycetes also have anti-inflammatory potential, they may be suitable to treat lung inflammation that often caused by COVID-19 infection.

\section{Herbicidal activity}

Herbicides are agents that are destructive to weeds or cause an alteration in their normal growth. The global herbicide market size is expected to reach overall market revenue of $\$ 7,998.9$ million by 2025 by growing at a CAGR of $4.8 \%$ during the said period. There are some reports of herbicidal properties of bioactive metabolites. Three new compounds such as erinachromanes A and B (124, 125) and erinaphenol A (126) with ten previously reported compounds [4(hydroxymethyl)-2-(3-methylbut-2-en-1-yl)phenol (127), eulatachromene (2,2-dimethyl-6hydroxymethylchromene) (128) (Fig. 8), 6-hydroxymethyl-2,2-dimethyl-chromanone, (129), 4chloro-3,5-dimethoxybenzaldehyde (130), methyl 4-chloro-3,5-dimethoxybenzoate (131) and 
(2S,3R,4S,5R)-2,4,5-trihydroxy-3-methoxyhexanoic acid (132), 5-(hydroxymethyl)furan 2carboxylate (133), and 4-hydroxyphenyl acetate (134), compound (135), compound (136) were purified from the culture broth of $H$. erinaceus (Fig. 9). All of these compounds significantly halted the growth of lettuce. Some of the compounds such as (134) and (135) inhibited the growth of hypocotyl at low doses ( 1 and $10 \mathrm{nmol} /$ paper) and exhibited poor activity at higher doses (100 nmol and $1 \mu \mathrm{mol} /$ paper). Among the chromans $(\mathbf{1 2 4}, \mathbf{1 2 5}, \mathbf{1 2 8}, \mathbf{1 2 9}),(\mathbf{1 2 8})$ showed the potent inhibitory activity against hypocotyl (at $1 \mu \mathrm{mol} /$ paper). Comparison of structures among (125) and (128) showed that the hydroxymethyl group at C-6 plays vital role in such activity. The compound (129) significantly ceased the growth of root (at $1 \mu \mathrm{mol} /$ paper). It suggests that the chromanone skeleton (129) has mail role in root growth inhibition. The compound (126) also showed similar activity like the compound (127), indicates the side chain at C-1' did not influence the growth regulation of plant. Among the dimethoxychlorobenzenes (130, 131, and 136), (136) exhibited the strongest inhibition of root growth (at $1 \mu \mathrm{mol} /$ paper). This suggests that the hydroxymethyl group is responsible for strengthening the inhibitory activity (Wu et al. 2019).

Two unique compounds, erinaceolactones A to B $(\mathbf{1 3 7}, \mathbf{1 3 8})$, and previously reported compounds 2-(hydroxymethyl)-6- methyl-4H-pyran-4-one (139), erinapyrones A (140) and B (141) and compound (142) were retrieved from the cultures of H. erinaceus (Fig. 9). Compounds such as (139 and 142) weakly inhibited the lettuce root growth $(1 \mu \mathrm{mol} / \mathrm{paper})$, while the compounds like (138, 140, and 141) showed inhibition at lower dose (100 nmol/paper). The lettuce hypocotyl growth was inhibited by the compounds (140 and 141) $1 \mu \mathrm{mol} / \mathrm{paper}$ and $100 \mathrm{nmol} / \mathrm{paper}$, respectively. The compound (139) inhibited the growth of root as well as hypocotyl at lower doses (1 and $10 \mathrm{nmol} /$ paper, respectively), but no activity showed at the higher doses (100 nmol and 1 $\mu \mathrm{mol} /$ paper, respectively) (Wu et al. 2015).<smiles>COc1cc(CO)cc(OC)c1Cl</smiles><smiles>CC(=O)c1cc2c(cc1O)COC2=O</smiles>

Erinaceolactone $\mathrm{A}(137)$<smiles>CC1=CC(=O)C[C@@H](CO)O1</smiles>

Erinapyrones B (141)<smiles>CC(O)c1cc2c(cc1O)COC2=O</smiles>

Erinaceolactone B (138)<smiles>Cc1oc(CO)cc(=O)c1CO</smiles>

Compound (142)

2-(hydroxymethyl)-6- methyl $-4 \mathrm{H}-$ pyran-4-one (139)

Erinapyrones A (140)

Fig. 9 - Herbicidal compounds isolated from Hericium erinaceus

\section{Conclusion}

Hericium erinaceus is an edible mushroom with a long history of use in traditional Chinese medicine. It has the capacity to prevent or alleviate or cure major diseases such as cancers, diabetes, lipidemia and depression including the neurodegenerative diseases. Many bioactive metabolites from $H$. erinaceus have been isolated as well as characterized by advanced techniques. Important metabolites characterized include hericenones, erinacine terpenoids, isoindolinones, and sterols. They possess diverse pharmacological properties such as antibiotic, anticarcinogenic, antidiabetic, hepatoprotective, nephroprotective and neuroprotective properties such as improvement of anxiety, cognitive function, and depression. Some of the compounds isolated from $H$. erinaceus possess herbicidal activity. Erinacines have potential neuroprotective properties, hericerins possess potent cytotoxic activity; sterols have anti-inflammatory and antiproliferative 
properties, while erinaceolactones inhibit hypocotyl as well as root growth of lettuce at very low concentrations. Although a large number of compounds were obtained from Hericium with moderate to potent biological activities, rational derivatization and high-throughput screening are warranted. Such attempts help to follow NGF, anticancer and anti-inflammatory activities, and the molecules with superior activity profiles could be employed for various pharmaceutical applications. It is warranted to understand their individual as well as synergistic actions, with specific attention towards in vivo dynamics as well as in vivo and clinical experiments.

There is a great demand to use different strategies to isolate the new compounds because conventionally used methods results in production of known compounds. Highly diverse secondary-metabolite production could be achieved by simple approach as one strain many compounds (OSMAC). Such approach needs varied media composition (metal ion concentration salinity and $\mathrm{C} / \mathrm{N}$ ratio) and fermentation conditions (solid/liquid, static/dynamic, $\mathrm{pH}$, temperature and oxygen level). The other methods can be co-cultivation/mixed fermentation and addition of enzyme inhibitors including precursor/s. The approach of co-cultivation of fungi mimics the ecological conditions, where the two or more interacting partners involve in fermentation process, which leads to production of new metabolites (Moussa et al. 2020, Sari et al. 2020). Similarly, another approach could be followed include incorporate of different biosynthetic precursors in to the fermentation media, which alters the biosynthetic pathways of secondary metabolites (Ramm et al. 2017). With the implementation of approaches like genetic engineering, metabolic engineering, and fermentation technology help producing value added compounds from fungi. The diverse metabolites of $H$. erinaceus with potential biological activities provide ample opportunities to develop versatile compounds. Such novel compounds could be assessed for pharmacological potential to treat dreadful diseases like Alzheimer's and cancer. In addition, a combination of existing drugs with $H$. erinaceus metabolites may also provide new insights towards efficient solutions to combat the lifestyle diseases.

\section{References}

Aloe L, Rocco ML, Bianchi P, Manni L. 2012 - Nerve growth factor: from the early discoveries to the potential clinical use. Journal of translational medicine 10 (1), 1-15. doi: 10.1186/14795876-10-239

Alzheimer's Association. 2019 - 2019 Alzheimer's disease facts and figures. Alzheimer's \& dementia, 15 (3), 321-387.

Amara I, Scuto M, Zappalà A, Ontario ML et al. 2020 - Hericium erinaceus prevents DEHPinduced mitochondrial dysfunction and apoptosis in PC12 cells. International journal of molecular sciences 21 (6), 2138. doi: 10.3390/ijms21062138

Ashour A, Amen Y, Allam AE, Kudo T et al. 2019 - New isoindolinones from the fruiting bodies of the fungus Hericium erinaceus. Phytochemistry Letters 32, 10-14.

Chan YC, Chen CC, Lee LY, Chen WP. 2019 - Active substances for preventing hearing deterioration, the composition containing the active substances, and the preparation method thereof. U.S. Patent 10,405,504.

Chen B, Han J, Bao L, Wang W. 2020 - Identification and $\alpha$-glucosidase inhibitory activity of meroterpenoids from Hericium erinaceus. Planta medica 86 (08), 571-578.

Chen CC, Tzeng TT, Chen CC, Ni CL et al. 2016 - Erinacine S, a rare sesterterpene from the mycelia of Hericium erinaceus. Journal of Natural Products 79 (2), 438-441.

Chen L, Yao JN, Chen HP, Zhao ZZ et al. 2018 - Hericinoids A-C, cyathane diterpenoids from culture of mushroom Hericium erinaceus. Phytochemistry Letters 27, 94-100.

Chiu CH, Chyau CC, Chen CC, Lee LY et al. 2018 - Erinacine A-enriched Hericium erinaceus mycelium produces antidepressant-like effects through modulating BDNF/PI3K/Akt/GSK-3 $\beta$ signaling in mice. International Journal of Molecular Sciences 19 (2), 341. doi: 10.3390/ijms19020341 
Dheda K, Lenders L, Magombedze G, Srivastava S, Raj P, et al. 2018 - Drug-penetration gradients associated with acquired drug resistance in patients with Tuberculosis. American Journal of Respiratory and Critical Care Medicine 198 (9), 1208-1219.

Diling C, Chaoqun Z, Jian Y, Jian L et al. 2017 - Immunomodulatory activities of a fungal protein extracted from Hericium erinaceus through regulating the gut microbiota. Frontiers in Immunology 8, 666. Doi: 10.3389/fimmu.2017.00666

Durmus A, Durmus I, Bender O, Karatepe O. 2021 - The effect of Hericium erinaceum on the prevention of chemically induced experimental colitis in rats. The Korean Journal of Internal Medicine 36 (Suppl. 1), S44-S52.

Hu JH, Li I, Lin TW, Chen WP et al. 2019 - Absolute bioavailability, tissue distribution, and excretion of erinacine $S$ in Hericium erinaceus mycelia. Molecules 24 (8), 1624. doi: 10.3390/molecules24081624

Kawagishi H, Ando M, Mizuno T. 1990 - Hericenone A and B as cytotoxic principles from the mushroom Hericium erinaceum. Tetrahedron Letters 31, 373-376.

Kawagishi H, Ando M, Sakamoto H, Yoshida S et al. 1991 - Hericenones C, D and E, stimulators of nerve growth factor (NGF)-synthesis from the mushroom Hericium erinaceum. Tetrahadron Letters 32, 4561-4564.

Kawagishi H, Ando M, Shinba K, Sakamoto H et al. 1993 - Chromans, hericenones F, G and H from the mushroom Hericium erinaceum. Phytochemistry 32, 175-178.

Kawagishi H, Kojima F, Okamoto K. 1995 - JP 7070168

Kawagishi H, Masui A, Tokuyama S, Nakamura T. 2006 - Erinacines J and K from the mycelia of Hericium erinaceum. Tetrahedron 62 (36), 8463-8466.

Kawagishi H, Shimada A, Hosokawa S, Mori H et al. 1996a - Erinacines E, F, and G, stimulators of nerve growth factor (NGF)-synthesis, from the mycelia of Hericium erinaceum. Tetrahedron Letters 37 (41), 7399-7402.

Kawagishi H, Shimada A, Shirai, R., Okamoto, K et al. 1994 - Erinacines A, B and C, strong stimulators of nerve growth factor (NGF)-synthesis, from the mycelia of Hericium erinaceum. Tetrahedron letters 35 (10), 1569-1572.

Kawagishi H, Shirai R, Sakamoto H, Yoshida S et al. 1992 - Erinapyrones A and B from the cultured mycelia of Hericium erinaceum. Chemistry Letters 21, 2475-2476.

Kawagishi H, Simada A, Shizuki K, Ojima F et al. 1996b - Erinacine D, a stimulator of NGFsynthesis, from the mycelia of Hericium erinaceum. Heterocyclic Communications 2 (1), 5154.

Kenmoku H, Kato N, Shimada M, Omoto M et al. 2001 - Isolation of (-)-cyatha-3,12-diene, a common biosynthetic intermediate of cyathane diterpenoids, from an erinacine-producing basidiomycete, Hericium erinaceum. Tetrahedron letters 42, 7439-7422.

Kim KH, Noh HJ, Choi SU, Lee KR. 2012 - Isohericenone, a new cytotoxic isoindolinone alkaloid from Hericium erinaceum. The Journal of Antibiotics 65 (11), 575-577.

Kim SP, Kang MY, Choi YH, Kim JH et al. 2011 - Mechanism of Hericium erinaceus (Yamabushitake) mushroom-induced apoptosis of U937 human monocytic leukemia cells. Food and Function 2 (6), 348-356.

Kolotushkina EV, Moldavan MG, Voronin KY, Skibo GG. 2003 - The influence of Hericium erinaceus extract on myelination process in vitro. Fiziologichnyi Zhurnal 49 (1), 38-45.

Kuo HC, Lu CC, Shen CH, Tung SY, et al. 2016 - Hericium erinaceus mycelium and its isolated erinacine A protection from MPTP-induced neurotoxicity through the ER stress, triggering an apoptosis cascade. J Transl Med. 14:78. doi: 10.1186/s12967-016-0831-y.

Kuo H, Kuo Y, Lee K, Hsieh M et al. 2017 - A comparative proteomic analysis of Erinacine A's inhibition of gastric cancer cell viability and invasiveness. Cellular Physiology and Biochemistry 43, 195-208.

Kushairi N, Phan CW, Sabaratnam V, David P et al. 2019 - Lion's mane mushroom, Hericium erinaceus (Bull.: Fr.) Pers. suppresses H2O2-induced oxidative damage and LPS-induced 
inflammation in HT22 hippocampal neurons and BV2 microglia. Antioxidants 8 (8), 261. doi: 10.3390/antiox 8080261

Lai PL, Naidu M, Sabaratnam V, Wong KH et al. 2013 - Neurotrophic properties of the Lion's mane medicinal mushroom, Hericium erinaceus (Higher Basidiomycetes) from Malaysia. International Journal of Medicinal Mushrooms 15 (6), 539-554.

Lee EW, Shizuki K, Hosokawa S, Suzuki M et al. 2000 - Two novel diterpenoids, erinacines H and I from the mycelia of Hericium erinaceum. Bioscience Biotechnology and Biochemistry 64 (11), 2402-2405.

Lee K, Lee KF, Tung S, Huang W et al. 2019 - Induction apoptosis of erinacine A in human colorectal cancer cells involving the expression of TNFR, Fas, and Fas ligand via the $\mathrm{JNK} / \mathrm{p} 300 / \mathrm{p} 50$ signaling pathway with histone acetylation. Frontiers in Pharmacology 10, 1174. doi.org/10.3389/fphar.2019.01174

Lee KF, Chen JH, Teng CC, Shen CH et al. 2014 - Protective effects of Hericium erinaceus mycelium and its isolated erinacine A against ischemia-injury-induced neuronal cell death via the inhibition of iNOS/p38 MAPK and nitrotyrosine. International Journal of Molecular Sciences 15 (9), 15073-15089.

Lee SK, Ryu SH, Turk A, Yeon SW et al. 2020 - Characterization of $\alpha$-glucosidase inhibitory constituents of the fruiting body of lion's mane mushroom (Hericium erinaceus). Journal of Ethnopharmacology 262, 113197. doi: 10.1016/j.jep.2020.113197

Lee SR, Jung K, Noh HJ, Park YJ et al. 2015 - A new cerebroside from the fruiting bodies of Hericium erinaceus and its applicability to cancer treatment. Bioorganic \& Medicinal Chemistry Letters 25 (24), 5712-5715.

Lew SY, Yow YY, Lim LW, Wong KH. 2020 - Antioxidant-mediated protective role of Hericium erinaceus (Bull.: Fr.) Pers. against oxidative dam- age in fbroblasts from Friedreich's ataxia patient. Food Science and Technology 40 (Suppl. 1), 264-272.

Li G, Yu K, Li F, Xu K et al. 2014a - Anticancer potential of Hericium erinaceus extracts against human gastrointestinal cancers. Journal of Ethnopharmacology 153 (2), 521-530.

Li I, Chang HH, Lin CH, Chen WP et al. 2020 - Prevention of early Alzheimer's disease by erinacine A-enriched Hericium erinaceus mycelia pilot double-blind placebo-controlled study. Frontiers in Aging Neuroscience 12, 155. doi: 10.3389/fnagi.2020.00155

Li I, Lee LY, Tzeng TT, Chen WP et al. 2018 - Neurohealth properties of Hericium erinaceus mycelia enriched with erinacines. Behavioural Neurology 2018, 5802634. doi: $10.1155 / 2018 / 5802634$

Li IC, Chen YL, Chen WP, Lee LY et al. 2014b - Genotoxicity profile of erinacine A-enriched Hericium erinaceus mycelium. Toxicology reports 1, 1195-1201.

Li IC, Chen YL, Lee LY, Chen WP et al. 2014c - Evaluation of the toxicological safety of erinacine A-enriched Hericium erinaceus in a 28-day oral feeding study in Sprague-Dawley rats. Food and Chemical Toxicology 70, 61-67.

Li IC, Lee LY, Chen YJ, Chou MY et al. 2019 - Erinacine A-enriched Hericium erinaceus mycelia promotes longevity in Drosophila melanogaster and aged mice. PloS one 14 (5), e0217226. doi: org/10.1371/journal.pone.0217226

Li W, Zhou W, Cha JY, Kwon SU et al. 2015b - Sterols from Hericium erinaceum and their inhibition of TNF- $\alpha$ and NO production in lipopolysaccharide-induced RAW 264.7 cells. Phytochemistry 115, 231-238.

Li W, Zhou W, Kim EJ, Shim SH et al. 2015a - Isolation and identification of aromatic compounds in Lion's Mane Mushroom and their anticancer activities. Food Chemistry 170, 336-342.

Liang B, Guo Z, Xie F, Zhao A. 2013 - Antihyperglycemic and antihyperlipidemic activities of aqueous extract of Hericium erinaceus in experimental diabetic rats. BMC Complementary and Alternative Medicine 13 (1), 253. Doi 10.1186/1472-6882-13-253

Liu JH, Li L, Shang XD, Zhang JL et al. 2016 - Anti-Helicobacter pylori activity of bioactive components isolated from Hericium erinaceus. Journal of Ethnopharmacology 183, 54-58. 
Lockhart SR, Guarner J. 2019 Emerging and reemerging fungal infections. Seminars in Diagnostic Pathology 36 (3), 177-181.

Lu QQ, Tian JM, Wei J, Gao JM. 2014 - Bioactive metabolites from the mycelia of the basidiomycete Hericium erinaceum. Natural Product Research 28 (16), 1288-1292.

Ma BJ, Ma JC, Ruan Y. 2012 - Hericenone L, a new aromatic compound from the fruiting bodies of Hericium erinaceums. Chinese Journal of Natural Medicines 10 (5), 363-365.

Ma BJ, Shen JW, Yu HY, Ruan Y et al. 2010 - Hericenones and erinacines: stimulators of nerve growth factor (NGF) biosynthesis in Hericium erinaceus. Mycology 1 (2), 92-98.

Ma BJ, Zhou Y, Li LZ, Li HM et al. 2008 - A new cyathane-xyloside from the mycelia of Hericium erinaceum. Zeitschrift für Naturforschung B 63 (10), 1241-1242.

Mishra R, Goel M, Barrow CJ, Deshmukh SK. 2020 - Endophytic fungi - an untapped source of potential antioxidants. Current Bioactive Compounds 16 (7), 944-964.

Mori K, Inatomi S, Ouchi K, Azumi Y et al. 2009 - Improving effects of the mushroom Yamabushitake (Hericium erinaceus) on mild cognitive impairment: A double-blind placebo-controlled clinical trial. Phytotherapy Research 23 (3), 367-372.

Mori K, Kikuchi H, Obara Y, Iwashita M et al. 2010 - Inhibitory effect of hericenone B from Hericium erinaceus on collagen-induced platelet aggregation. Phytomedicine 17 (14), 10821085.

Mori K, Obara Y, Hirota M, Azumi Y et al. 2008 - Nerve growth factor-inducing activity of Hericium erinaceus in 1321N1 human astrocytoma cells. Biological and Pharmaceutical Bulletin 31 (9), 1727-1732.

Mori K, Obara Y, Moriya T, Inatomi S et al. 2011 - Effects of Hericium erinaceus on amyloid $\beta$ (25-35) peptide-induced learning and memory deficits in mice. Biomedical Research 32 (1), $67-72$.

Mori K, Ouchi K, Hirasawa N. 2015 - The anti-inflammatory effects of lion's mane culinarymedicinal mushroom, Hericium erinaceus (higher basidiomycetes) in a coculture system of 3t3-L1 adipocytes and raw264 macrophages. International Journal of Medicinal Mushrooms $17,609-618$.

Moussa M, Ebrahim W, Kalscheuer R, Liu Z. et al. 2020 - Co-culture of the bacterium Pseudomonas aeruginosa with the fungus Fusarium tricinctum induces bacterial antifungal and quorum sensing signaling molecules. Phytochemistry Letters 36, 37-41.

Nagai K, Chiba A, Nishino T, Kubota T et al. 2006 - Dilinoleoyl-phosphatidylethanolamine from Hericium erinaceum protects against ER stress-dependent Neuro2a cell death via protein kinase C pathway. Journal of Nutritional Biochemistry 17 (8), 525-530.

Nagano M, Shimizu K, Kondo R, Hayashi C et al. 2010 - Reduction of depression and anxiety by 4 weeks Hericium erinaceus intake. Biomedical Research 31 (4), 231-237.

Nannini E, Murray BE, Arias C.A, 2010 - Resistance or decreased susceptibility to glycopeptides, daptomycin, and linezolid in methicillin-resistant Staphylococcus aureus. Current Opinion in Pharmacology 10 (5), 516-521.

Ngan LTM, Vi NT, Tham DTM, Ho PT et al. 2021 - Antioxidant and anti-Helicobacter pylori activities of Hericium erinaceus mycelium and culture filtrate. Biomedical Research and Therapy 8 (3), 4267-4276.

Ogurtsova K, da Rocha Fernandes JD, Huang Y, Linnenkamp U, Guariguata L, et al. (2017) IDF Diabetes Atlas: Global estimates for the prevalence of diabetes for 2015 and 2040. Diabetes Res Clin Pract. 128:40 - 50.

Phan CW, Lee GS, Hong SL, Wong YT et al. 2014 - Hericium erinaceus (Bull.: Fr) Pers. cultivated under tropical conditions: isolation of hericenones and demonstration of NGFmediated neurite outgrowth in PC12 cells via MEK/ERK and PI3K-Akt signaling pathways. Food \& Function 5 (12), 3160-3169.

Ramm S, Krawczyk B, Mühlenweg A, Poch A. et al. 2017 - A self-sacrificing N-methyltransferase is the precursor of the fungal natural product omphalotin. Angewandte Chemie International Edition 56(33), 9994-9997. 
Rahman MA, Abdullah N, Aminudin N. 2014 - Inhibitory effect on in vitro LDL oxidation and HMG Co-a reductase activity of the liquid-liquid partitioned fractions of Hericium erinaceus (Bull.) persoon (Lion's Mane Mushroom). BioMed Research International 2014. doi: $10.1155 / 2014 / 828149$

Ratto D, Corana F, Mannucci B, Priori EC et al. 2019 - Hericium erinaceus improves recognition memory and induces hippocampal and cerebellar neurogenesis in frail mice during aging. Nutrients 11 (4), p 715. doi: 10.3390/nu11040715

Rupcic Z, Rascher M, Kanaki S, Köster RW et al. 2018 - Two new cyathane diterpenoids from mycelial cultures of the medicinal mushroom Hericium erinaceus and the rare species, Hericium flagellum. International Journal of Molecular Sciences 19 (3), p 740. doi: 10.3390/ijms19030740

Ryu S, Kim HG, Kim JY, Kim SY et al. 2018 - Hericium erinaceus extract reduces anxiety and depressive behaviors by promoting hippocampal neurogenesis in the adult mouse brain. Journal of Medicinal Food 21 (2), 174-180.

Ryu SH, Hong SM, Khan Z, Lee SK et al. 2021 - Neurotrophic isoindolinones from the fruiting bodies of Hericium erinaceus. Bioorganic \& Medicinal Chemistry Letters 31, 127714. doi: 10.1016/j.bmcl.2020.127714

Saito T, Aoki F, Hirai H, Inagaki T et al. 1998 - Erinacine E as a kappa opioid receptor agonist and its new analogs from a basidiomycete, Hericium ramosum. The Journal of Antibiotics 51, 983-990.

Salehi A, Delcroix JD, Swaab DF. 2004 - Alzheimer's disease and NGF signaling. Journal of Neural Transmission 111 (3), 323-345.

Sari M, Kusharyoto W, Brazia AC. 2020 - Profiling bioactive compounds in secondary metabolites from co-cultivation between actinomycetes and pathogenic bacteria. In IOP Conference Series: Earth and Environmental Science 4399 (1), 012009).

Shimada A, Kawagishi H, Furukawa A. 1996. JP 8073486

Song X, Gaascht F, Schmidt-Dannert C, Salomon CE. 2020 - Discovery of antifungal and biofilm preventative compounds from mycelial cultures of a unique North American Hericium sp. fungus. Molecules 25 (4), p 963. doi: 10.3390/molecules25040963

Sung H, Ferlay J, Siegel RL, Laversanne M et al. 2021. Global cancer statistics 2020: GLOBOCAN estimates of incidence and mortality worldwide for 36 cancers in 185 countries. CA: a cancer journal for clinicians 71 (3), pp.209-249.

Trovato A, Siracusa R, Di Paola R, Scuto M et al. 2016 - Redox modulation of cellular stress response and lipoxin A4 expression by Hericium erinaceus in rat brain: relevance to Alzheimer's disease pathogenesis. Immunity \& Ageing 13 (1), 1-11.

Tsai-Teng T, Chin-Chu C, Li-Ya L, Wan-Ping C et al. 2016 - Erinacine A-enriched Hericium erinaceus mycelium ameliorates Alzheimer's disease-related pathologies in APPswe/PS1dE9 transgenic mice. Journal of biomedical science 23 (1), 1-12.

Tung SY, Lee KC, Lee KF, Yang YL et al. 2021 - Apoptotic mechanisms of gastric cancer cells induced by isolated erinacine $\mathrm{S}$ through epigenetic histone $\mathrm{H} 3$ methylation of FasL and TRAIL. Food \& Function 12 (8), 3455-3468.

Tzeng TT, Chen CC, Chen CC, Tsay HJ et al. 2018 - The cyanthin diterpenoid and sesterterpene constituents of Hericium erinaceus mycelium ameliorate Alzheimer's disease-related pathologies in APP/PS1 transgenic mice. International Journal of Molecular Sciences 19 (2), p 598. doi: 10.3390/ijms19020598

Ueda K, Tsujimori M, Kodani S, Chiba A et al. 2008 - An endoplasmic reticulum (ER) stresssuppressive compounds and its analogues from the mushroom Hericium erinaceum. Bioorganic \& Medicinal Chemistry 16, 9467-9470.

Üstün R, Ayhan P. 2019 - Regenerative activity of Hericium erinaceus on axonal injury model using in vitro laser microdissection technique. Neurological Research 41 (3), 265-274. 
Venturella G, Ferraro V, Cirlincione F, Gargano ML. 2021 - Medicinal mushrooms: bioactive compounds, use, and clinical trials. International Journal of Molecular Sciences 22 (2), 634. doi: 10.3390/ijms22020634

Vigna L, Morelli F, Agnelli GM, Napolitano F et al. 2019 - Hericium erinaceus improves mood and sleep disorders inpatients affected by overweight or obesity: Could circulating pro-BDNF and BDNF be potential biomarkers? Evidence-Based Complementary and Alternative Medicine 2019. doi: 10.1155/2019/7861297

Wang G, Zhang X, Maier SE, Zhang L et al. 2019b - In vitro and in vivo inhibition of Helicobacter pylori by ethanolic extracts of lion's mane medicinal mushroom, Hericium erinaceus (Agaricomycetes). International Journal of Medicinal Mushrooms 21 (1). doi: 10.1615/IntJMedMushrooms.2018029487

Wang JC, Hu SH, Su CH, Lee TM. 2001 - Antitumor and immunoenhancing activities of polysaccharide from culture broth of Hericium spp. The Kaohsiung journal of medical sciences 17 (9), 461-467.

Wang K, Bao L, Ma K, Liu N et al. 2015b - Eight new alkaloids with PTP1B and $\alpha$-glucosidase inhibitory activities from the medicinal mushroom Hericium erinaceus. Tetrahedron 71 (51), 9557-9563.

Wang K, Bao L, Qi Q, Zhao F et al. 2015a - Erinacerins C-L, isoindolin-1-ones with $\alpha$-glucosidase inhibitory activity from cultures of the medicinal mushroom Hericium erinaceus. Journal of Natural Products 78, 146-154.

Wang LY, Huang CS, Chen YH, Chen CC et al. 2019a - Anti-inflammatory effect of erinacine C on NO production through down-regulation of NF- $\kappa \mathrm{B}$ and activation of Nrf2-mediated HO-1 in BV2 microglial cells treated with LPS. Molecules 24 (18), 3317. doi: 10.3390/molecules24183317

Wang XL, Xu KP, Long HP, Zou H et al. 2016 - New isoindolinones from the fruiting bodies of Hericium erinaceum. Fitoterapia 111, 58-65.

Wu J, Tokunaga T, Kondo M, Ishigami K et al. 2015 - Erinaceolactones A to C, from the culture broth of Hericium erinaceus. Journal of Natural Products 78 (1), 155-158.

Wu J, Uchida K, Ridwan AY, Kondo M et al. 2019 - Erinachromanes A and B and erinaphenol a from the culture broth of Hericium erinaceus. Journal of Agricultural and Food Chemistry 67 (11), 3134-3139.

Yang BK, Park JB, Song CH. 2003 - Hypolipidemic effect of an exo-biopolymer produced from a submerged mycelial culture of Hericium erinaceus. Bioscience Biotechnology and Biochemistry 67 (6), 1292-1298.

Yao W, Zhang JC, Dong C, Zhuang C et al. 2015 - Effects of amycenone on serum levels of tumor necrosis factor- $\alpha$, interleukin-10, and depression-like behavior in mice after lipopolysaccharide administration. Pharmacology Biochemistry and Behavior 136, 7-12.

Yi Z, Shao-Long Y, Ai-Hong W, Zhi-Chun S et al. 2015 - Protective effect of ethanol extracts of Hericium erinaceus on alloxan-induced diabetic neuropathic pain in rats. Evidence-Based Complementary and Alternative Medicine 2015:595480. doi: 10.1155/2015/595480

Yu Y, Hu Q, Liu J, Su A et al. 2021 - Isolation, purification and identification of immunologically active peptides from Hericium erinaceus. Food and Chemical Toxicology 151, 112111. doi: 10.1016/j.fct.2021.112111

Zhang CC, Cao CY, Kubo M, Harada K et al. 2017 - Chemical constituents from Hericium erinaceus promote neuronal survival and potentiate neurite outgrowth via the TrkA/Erk1/2 pathway. International Journal of Molecular Sciences 18 (8), 1659. doi: 10.3390/ijms 18081659

Zhang CC, Yin X, Cao CY, Wei J et al. 2015b - Chemical constituents from Hericium erinaceus and their ability to stimulate NGF-mediated neurite outgrowth on PC12 cells. Bioorganic \& Medicinal Chemistry Letters 25 (22), 5078-5082. 
Zhang F, Lv H, Zhang X. 2020 - Erinacerins, Novel Glioma Inhibitors from Hericium erinaceus, Induce Apoptosis of U87 Cells through Bax/Capase-2 Pathway. Anticancer Agents in Medicinal Chemistry 20 (17), 2082-2088.

Zhang Y, Liu L, Bao L, Yang Y et al. 2018 - Three new cyathane diterpenes with neurotrophic activity from the liquid cultures of Hericium erinaceus. The Journal of antibiotics 71 (9), 818-821.

Zhang Y. 2016 - Chemical Constituents of Hericium erinaceus, Northwest A \& F University, Xianyang, China. International Journal of Molecular Sciences 18 (8), 1659. doi: 10.3390/ijms 18081659

Zhang Z, Liu RN, Tang QJ, Zhang JS et al. 2015a - A new diterpene from the fungal mycelia of Hericium erinaceus. Phytochemistry Letters 11, 151-156. 